\title{
Full-scale fire testing to collapse of steel stiffened plate structures under lateral patch loading (Part 1) - without passive fire protection
}

\author{
Jeom Kee Paik ${ }^{\mathrm{a}, \mathrm{b}, \mathrm{c}^{*}}$, Min Gyu Ryu ${ }^{\mathrm{c}}$, Kunhou He ${ }^{\mathrm{b}}$, Dong Hun Lee ${ }^{\mathrm{c}}$, Seung Yul Lee ${ }^{\mathrm{a}}$, Dae \\ Kyeom Park ${ }^{\mathrm{a}}$, and Giles Thomas ${ }^{\mathrm{b}}$
}

${ }^{a}$ The Korea Ship and Offshore Reseach Institute, Pusan National University (Lloyd's Register Foundation Research Centre of Excellence), Busan, Republic of Korea

${ }^{\mathrm{b}}$ Department of Mechanical Engineering, University College London, London, UK

${ }^{c}$ Department of Naval Architecture and Ocean Engineering, Pusan National University, Busan, Republic of Korea

*Corresponding author. J.K. Paik. Email: j.paik@ucl.ac.uk

\begin{abstract}
The aim of this paper is to present a fire test database on the collapse of a full-scale steel stiffened plate structure without passive fire protection under lateral patch loading. Steel plate panels of a 1,900 TEU containership in compliance with test facility in a maximum size and capacity were considered as a reference structure, with principal dimensions of 7 $\mathrm{m}$ long and $4.8 \mathrm{~m}$ wide fitted with two transverse frames and seven longitudinal stiffeners. Lateral patch loading was applied using two loading actuators at the centre of each transverse frame. A fire test was conducted in a furnace fuelled by liquefied petroleum gas, where the maximum gas cloud temperature inside the furnace was increased up to $800{ }^{\circ} \mathrm{C}$ during testing. Time history of the lateral deformations of the test structure was measured with the focus on a critical period of time until the structure reached the ultimate limit state (or collapse) after the fires started. Details of the test database are documented, which will be useful for validating computational models for structural failure analysis in fires.
\end{abstract}

Keywords: Fire safety, full-scale fire test, structural collapse, structural failure, steel stiffened plate structures, steel plated structures, gas cloud temperature, steel temperature, passive fire protection

\section{Introduction}

Despite significant efforts at every stage of design, construction, operation, and decommissioning, accidents continue to occur in association with ships and offshore structures (Paik 2019). Over 70\% of accidents in offshore installations stem from fires and explosions (HSE 2002). The European Maritime Safety Agency (EMSA 2019) surveyed ship casualties and incidents with a total of 25,614 cases having occurred during 2011-2018, showing that over $75 \%$ of accidents were due to fires and explosions in some years.

In engineering structures involving hydrocarbons, explosions can occur when released hydrocarbons are ignited in a combination with an oxidizer (usually oxygen or air). This is a combustion process of hydrocarbon molecules with a high temperature, which react 
spontaneously with an oxidizer. Explosions typically result in a blast or a rapid increase in pressure, leading to structural failure. Fire, in contrast, is a combustible vapor or gas that combines with an oxidizer in a combustion process. Even without hydrocarbons involved, fires can occur due to friction of cargoes or spontaneous combustion. The evolution of light, heat, and flame is manifested by fires, potentially leading to structural failure. This paper focuses on the fire safety of steel plated structures such as ships and ship-shaped offshore structures in association with a critical period of time until structures in fires entirely collapse.

For fire safety engineering, structural failure characteristics must be identified by looking at how structures deform with time after fires start. They are a nonlinear problem associated with multiple physical processes, multiple scales and multiple criteria as similarity laws are unavailable to convert small-scale models to full-scale prototype structures. As such, full-scale or large-scale physical testing is highly demanding to capture fire physics and structural failure mechanism. Cong et al. (2005) performed a fire testing on the collapse of a large-scale steel I-girder. Whilst some fire tests on framed structure models in small or large-scales are reported in the literature (Wainman and Kirby 1987, BS 2014, ISO 1999, Rahmanian and Wang 2009), no full-scale fire testing on steel plated structures has previously been conducted.

The aim of this paper is to contribute to producing a fire test database on the collapse of a full-scale steel stiffened plate structure. The test database will be useful to validate computational models for structural failure analysis in fires. A separate article as a sequel to this paper is being prepared where the effects of passive fire protection on the collapse of the same structure are investigated (Paik et al. 2020c).

\section{Design of the test structure}

Figure 1 shows steel plate panels of an as-built containership carrying 1,900 TEU, selected as a reference ship in compliance with test facility in size and capacity. Figure 2 denotes the nomenclature of the test structure. Properties of plate panels are characterised by the plate slenderness ratio, $\beta$ and the column slenderness ratio of longitudinal stiffeners with attached plating, $\lambda$, as follows.

$$
\begin{gathered}
\beta=\frac{b}{t} \sqrt{\frac{\sigma_{Y}}{E}} \\
\lambda=\frac{a}{\pi r} \sqrt{\frac{\sigma_{Y}}{E}}
\end{gathered}
$$

where $a$ is the length of plating (or spacing between transverse frames), $b$ is the breadth of plating (or spacing between longitudinal stiffeners), $t$ is the thickness of plating, $E$ is the Young's modulus, $\sigma_{Y}$ is the yield stress of material, and $r$ is the radius of gyration 
of longitudinal stiffener with attached plating which is taken as $\sqrt{I / A}$ with the moment of inertia, $I$ and the cross-sectional area, $A$.

The scantlings of the test structure, which is made of high tensile steel with grade AH32, were determined. Figure 3 shows the plan view drawing of the test structure design. Table 1 compares the geometric properties for a reference plate panel versus the test structure.

To attain a strong support condition along four edges (boundaries) of the test structure associated with the furnace facility, support jigs were also designed and constructed. Figure 4 shows the plan and profile drawings of the support jigs which were made of the same high tensile steel with grade AH32 as for the test structure. The support jigs may represent a fixed boundary condition for the structural failure analysis using computational models.
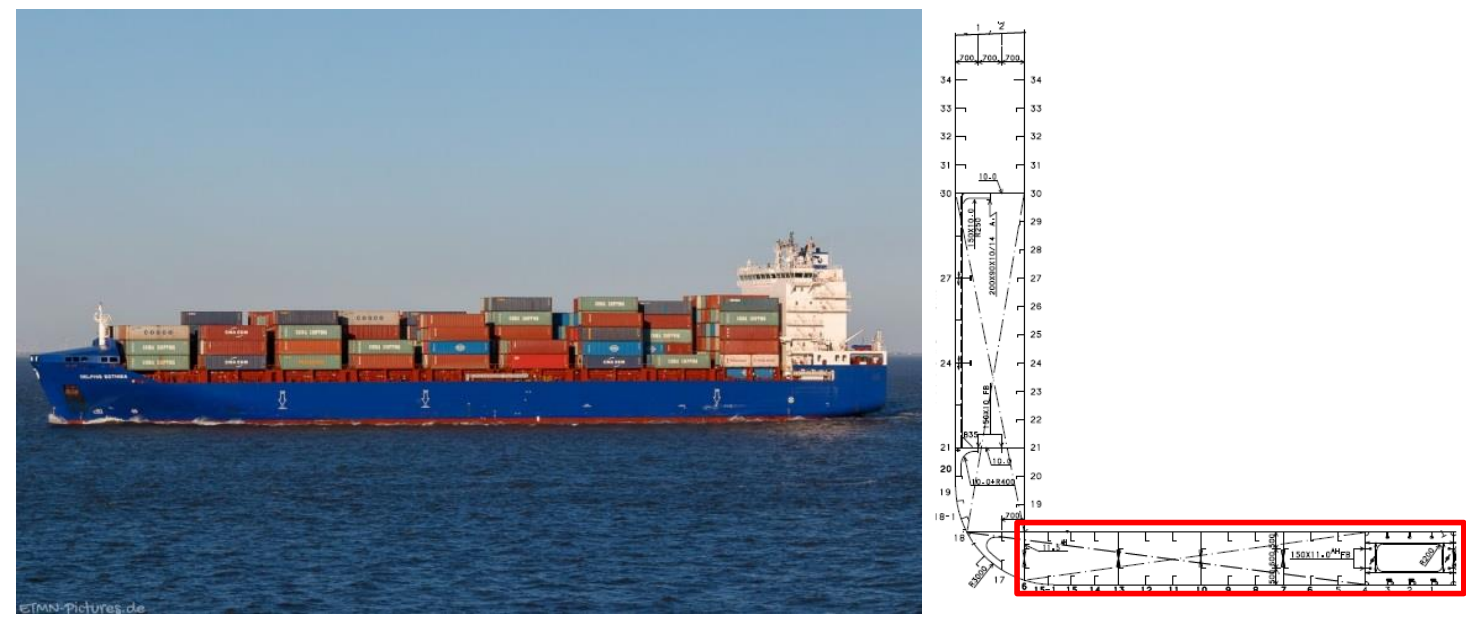

Figure 1. A 1,900 TEU containership built by Hanjin Heavy Industries, selected as a reference in the present paper.
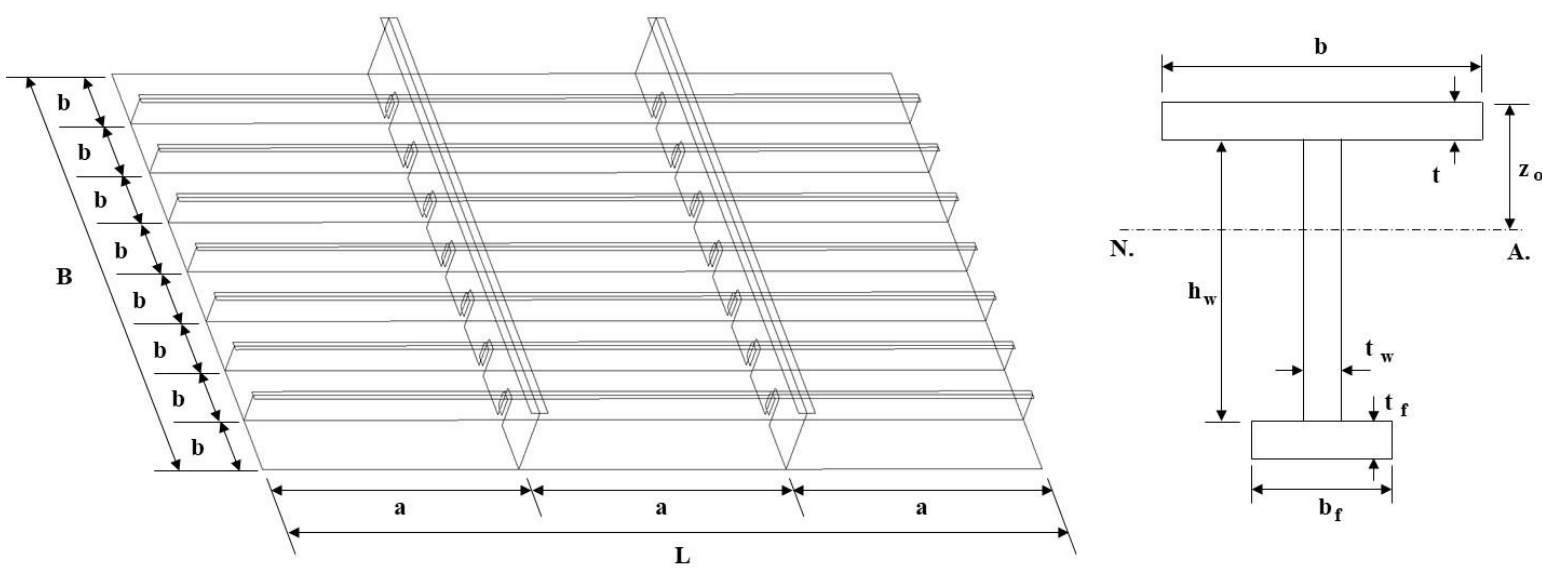

Figure 2. Nomenclature of the test structure. 


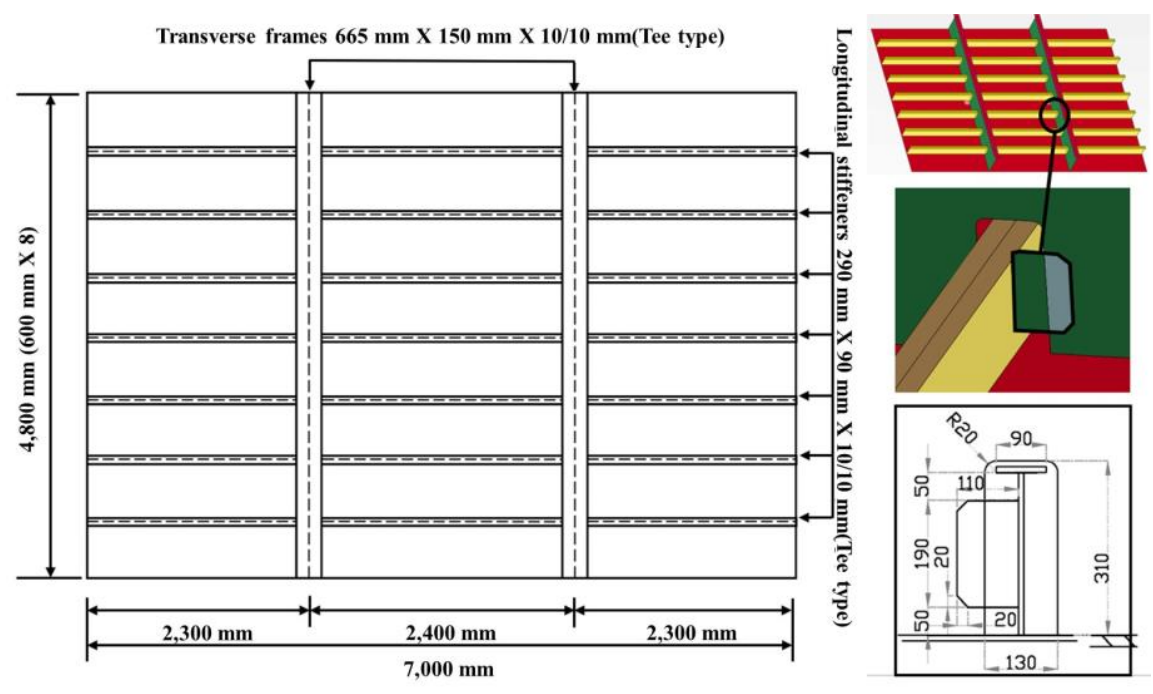

Figure 3. Plan view drawing of the test structure design, with detail of the longitudinal stiffener and cut out.

Table 1. Dimensions of plate panels for the reference ship structure versus the test structure.

\begin{tabular}{|l|l|l|}
\hline \multicolumn{1}{|c|}{ Parameter } & \multicolumn{1}{|c|}{ Reference plate panels } & \multicolumn{1}{c|}{ Test structure } \\
\hline Material & AH32 & AH32 \\
\hline Length, $L$ & $9,450 \mathrm{~mm}$ & $7,000 \mathrm{~mm}$ \\
\hline Breadth, $B$ & $6,912 \mathrm{~mm}$ & $4,800 \mathrm{~mm}$ \\
\hline $\begin{array}{l}\text { Spacing between } \\
\text { transverse frames, } a\end{array}$ & $3,150 \mathrm{~mm}$ & $2,400 \mathrm{~mm}$ \\
\hline $\begin{array}{l}\text { Spacing between } \\
\text { longitudinal stiffeners, } \\
b\end{array}$ & $864 \mathrm{~mm}$ & $600 \mathrm{~mm}$ \\
\hline $\begin{array}{l}\text { Number of longitudinal } \\
\text { stiffeners }\end{array}$ & 7 & 7 \\
\hline Aspect ratio, $a / b$ & 3.65 & 4.00 \\
\hline Plate thickness, $t$ & $12 \mathrm{~mm}$ & $10 \mathrm{~mm}$ \\
\hline $\begin{array}{l}\text { Plate slenderness ratio, } \\
\beta\end{array}$ & 2.89 & 2.41 \\
\hline $\begin{array}{l}\text { Size of longitudinal } \\
\text { stiffener }\end{array}$ & $283 \times 90 \times 13 / 17(\mathrm{~T})(\mathrm{mm})$ & $290 \times 90 \times 10 / 10(\mathrm{~T})(\mathrm{mm})$ \\
\hline $\begin{array}{l}\text { Column slenderness } \\
\text { ratio, } \lambda\end{array}$ & 0.38 & 0.28 \\
\hline $\begin{array}{l}\text { Size of transverse } \\
\text { frame }\end{array}$ & $665 \times 150 \times 10 / 10(\mathrm{~T})(\mathrm{mm})$ & $665 \times 150 \times 10 / 10(\mathrm{~T})(\mathrm{mm})$ \\
\hline $\begin{array}{l}\text { Number of transverse } \\
\text { frames }\end{array}$ & 2 & 2 \\
\hline Weight & $9.5 \mathrm{tonnes}(9.4505)$ & $4.7 \mathrm{tonnes}$ \\
\hline
\end{tabular}



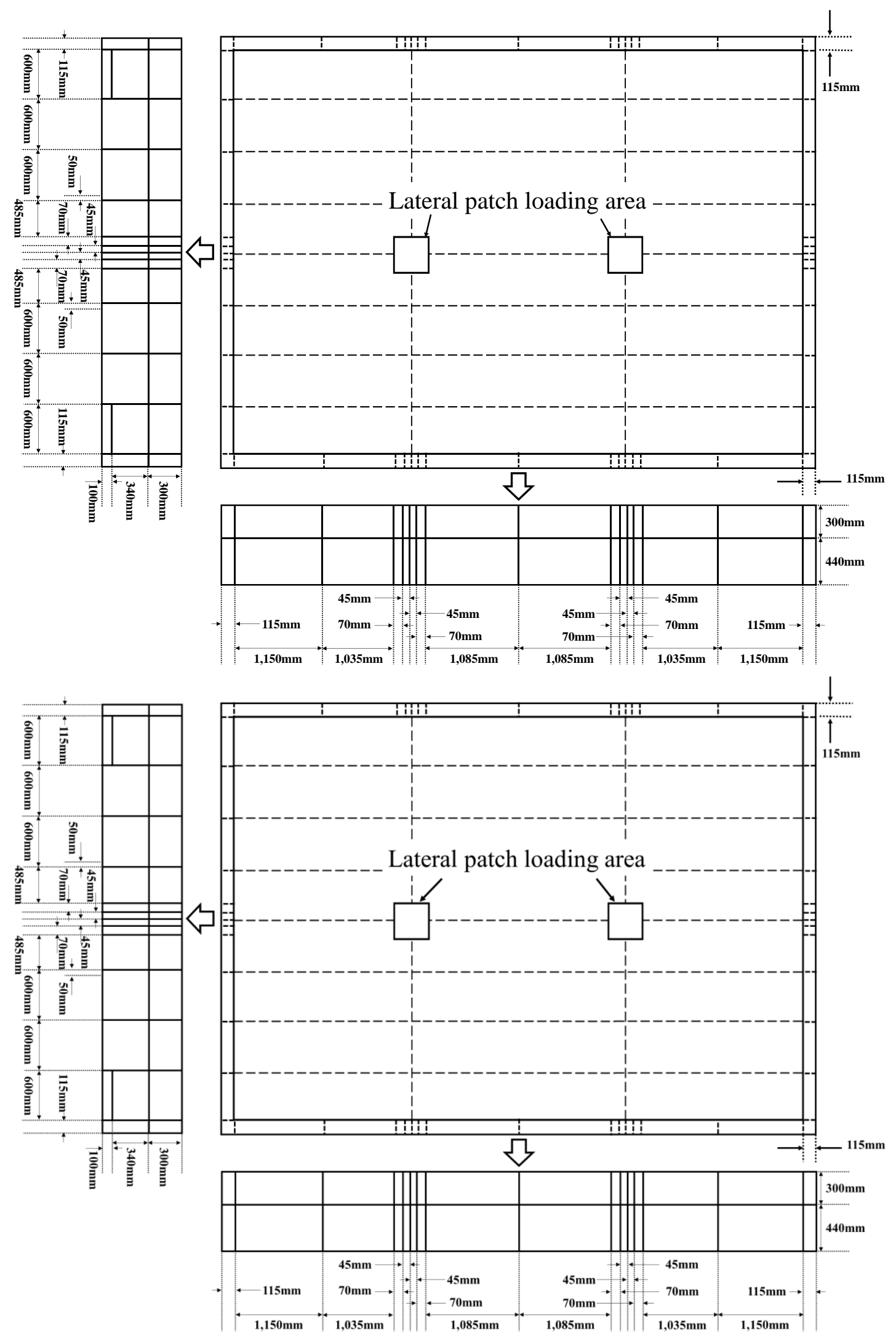

Figure 4. Plan and profile drawings of the test structure together with supporting jigs along the four edges. 


\section{Material procurement}

A high tensile steel with grade AH32 was used to fabricate the test structure and support jigs. Material procurement was conducted under the responsibility of a shipyard in Busan, South Korea which fabricated the test structure as described in Section 4. The nominal values of mechanical properties for $\mathrm{AH} 32$ high tensile steel at room temperature $\left(20{ }^{\circ} \mathrm{C}\right)$, provided by the steel maker, are indicated in Table 2 . Figure 5 presents the effects of elevated temperatures on mechanical properties of steel (EN 1993-1-2 2005).

As the test database obtained from the present study will be used to validate computational models for structural failure analysis in fires, the actual mechanical properties of material used for fabricating the test structure need to be identified. Furthermore, material properties significantly vary with elevated temperatures in fires, as presented in Figure 5, and thus they should also be characterised. The reduction factor in Figure 5 indicates a ratio of the corresponding parameter at an elevated temperature to that at room temperature.

After the material procurement, tensile material test specimens with a round rod (bar) type were extracted from the plate sheet in accordance with ASTM specifications. ASTM International (2020), formerly known as American Society for Testing and Materials, is an international standards organisation that develops and publishes voluntary consensus technical standards for a wide range of materials, products, systems, and services. ASTM E8/E8M-16a standard was applied for room temperature $\left(20{ }^{\circ} \mathrm{C}\right)$ test and E21-17 standard was applied for elevated temperatures $\left(400{ }^{\circ} \mathrm{C}, 600{ }^{\circ} \mathrm{C}\right.$ and $\left.800{ }^{\circ} \mathrm{C}\right)$. To characterise the effects of elevated temperatures due to fires on the mechanical properties of material, tensile testing was conducted with varying elevated temperatures using universal test machine with a temperature control chamber.

Figure 6 shows a tensile material test set-up at an elevated temperature using the test facility at the ICASS/KOSORI in Yangsan, South Korea (www.icass.center). Figure 7 presents the engineering stress-engineering strain curves of the high tensile steel AH32 obtained from the tensile testing. It is observed that neither upper nor lower yield point appears at $400{ }^{\circ} \mathrm{C}$ until the ultimate tensile strength is reached. In this case, the yield strength was defined as a stress at the intersection of the stress-strain curve and a straight line through an offset point strain, equivalent to the proof stress at $0.2 \%$ strain (Paik 2018). Table 3 summarises the obtained mechanical properties of the AH32 steel, with varying elevated temperatures associated with fires.

Table 2. Nominal properties of AH32 high tensile steel at room temperature $\left(20{ }^{\circ} \mathrm{C}\right)$, provided by steel maker.

\begin{tabular}{|l|l|l|l|}
\hline $\begin{array}{l}\text { Elastic modulus, } \\
E(\mathrm{GPa})\end{array}$ & Yield strength, $\sigma_{Y}(\mathrm{MPa})$ & $\begin{array}{l}\text { Ultimate tensile } \\
\text { strength, } \sigma_{T}(\mathrm{MPa})\end{array}$ & $\begin{array}{l}\text { Fracture strain } \\
\text { (elongation), } \\
\varepsilon_{f}\end{array}$ \\
\hline 200 & $\geq 315$ & $440-570$ & $\geq 0.22$ \\
\hline
\end{tabular}




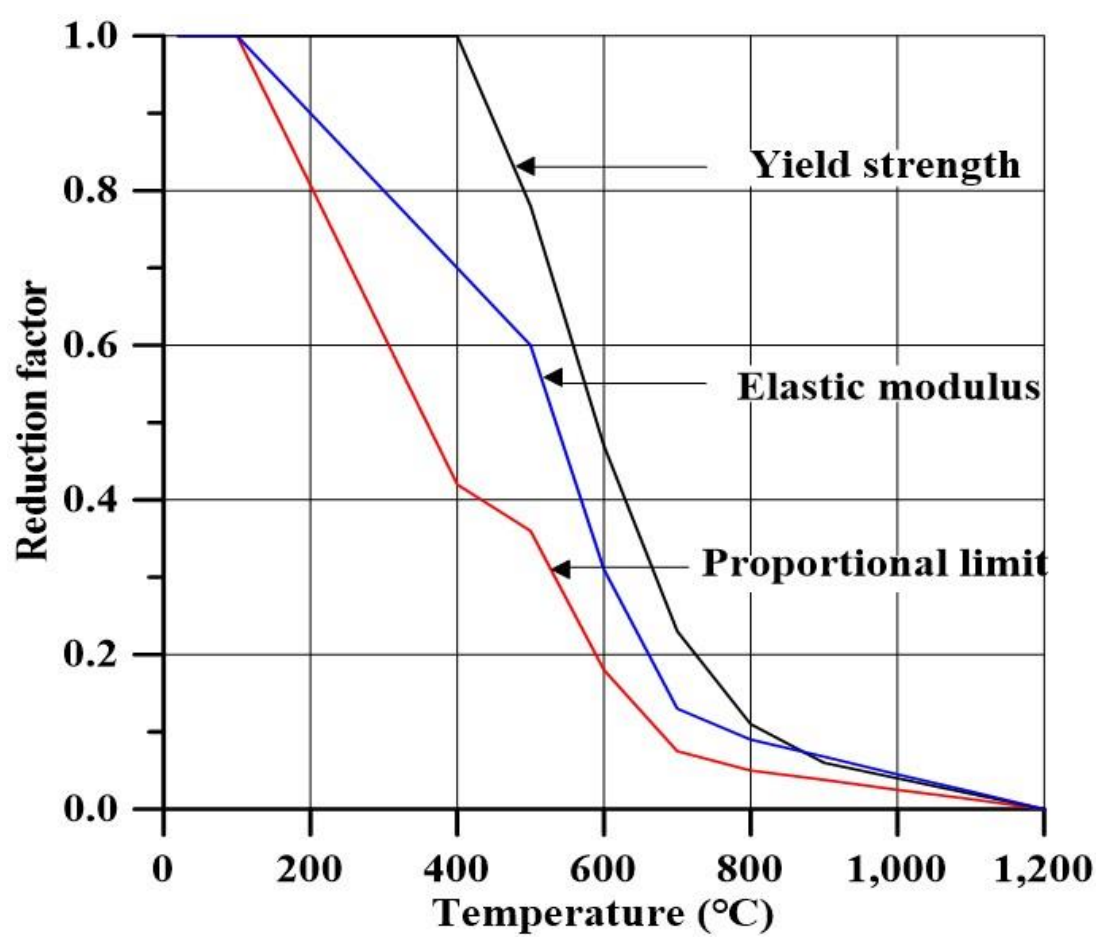

Figure 5. Effect of elevated temperatures on mechanical properties of steel (EN 1993-1-2 2005).

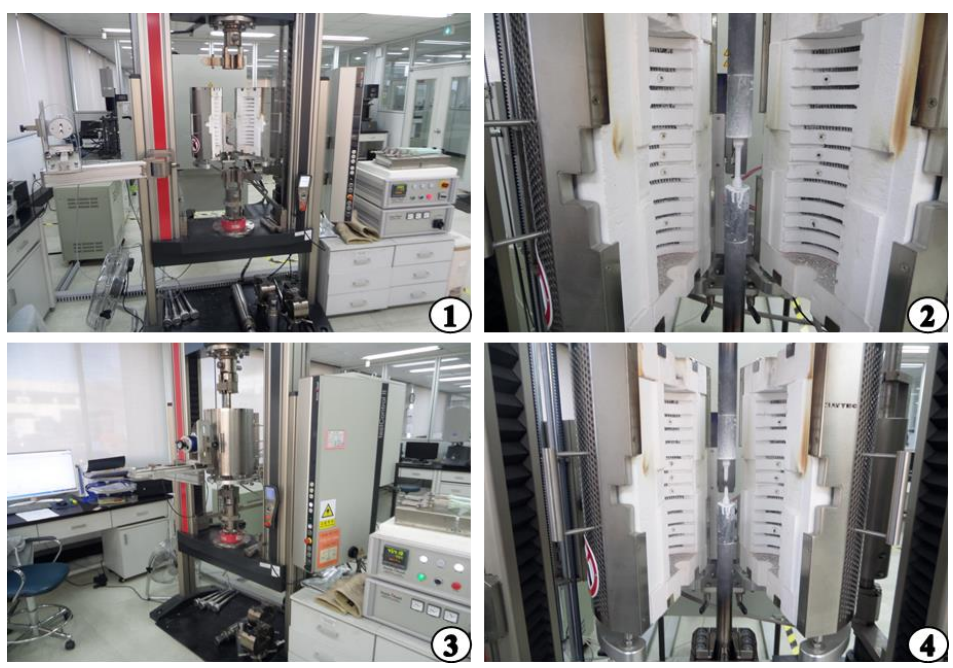

Figure 6. Tensile material test set-up using universal testing machine with an elevated temperature control chamber. 

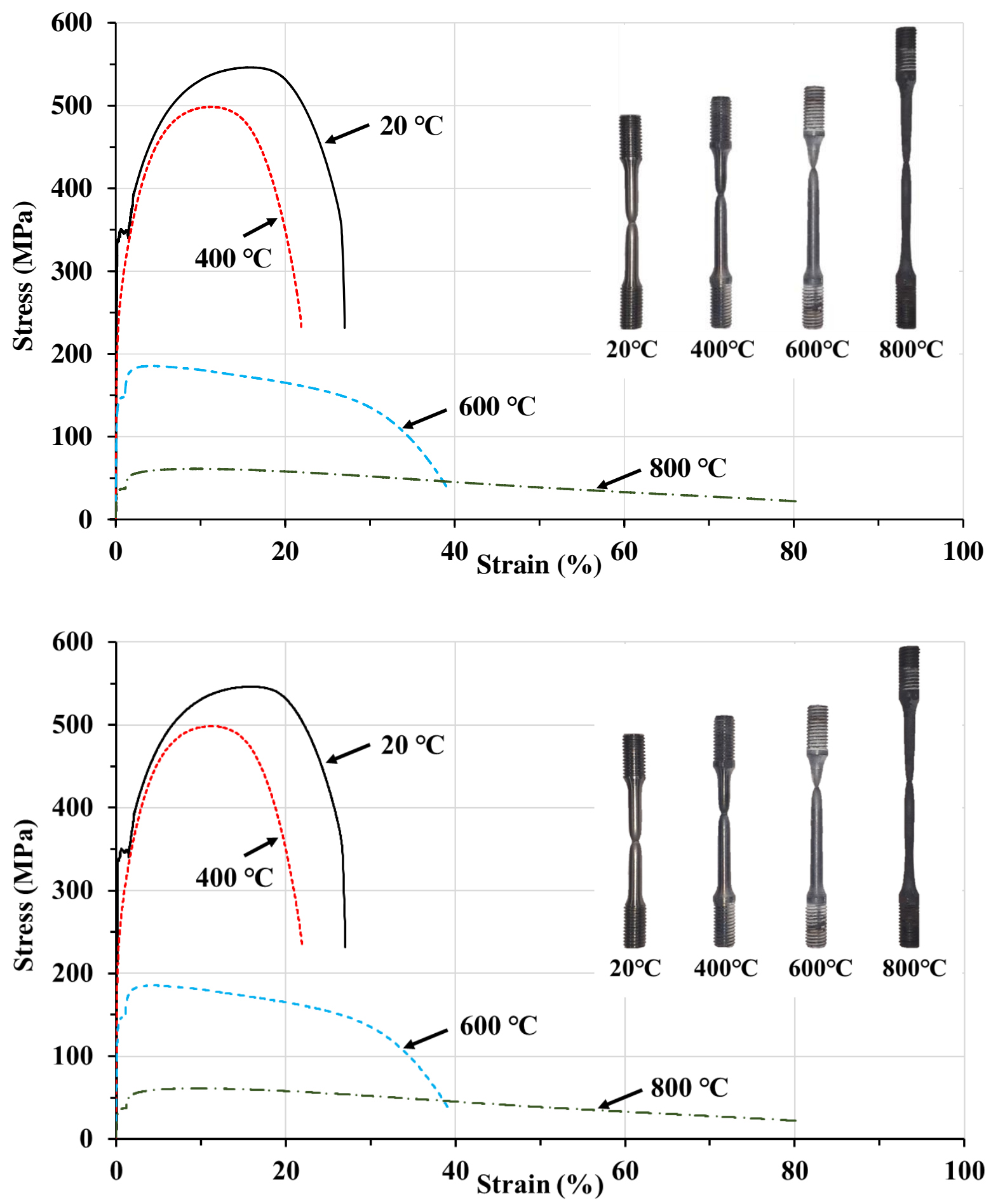

Figure 7. Engineering stress-engineering strain curves of high tensile steel AH32 at different temperatures, obtained from tensile tests.

Figure 8 shows a comparison of material properties between tension tests and EN 1993-1-2 (2005), where the nominalised factor indicates a ratio of the corresponding parameter at an elevated temperature to that at room temperature. It is confirmed from Figure 8 that the EN 1993-1-2 curve generally provides a reasonable guideline to 
characterise the effects of elevated temperatures on mechanical properties of steel, as it is in a good agreement with tension tests. New data for ultimate tensile strength and elongation obtained from the present study are also presented. The reduction trend of ultimate tensile strength is quite similar to that of yield strength, but the elongation significantly increases with increase in temperature.

Table 3. Mechanical properties of high tensile steel AH32 at different temperatures.

\begin{tabular}{|l|l|l|l|l|}
\hline Temperature & $20^{\circ} \mathrm{C}$ & $400{ }^{\circ} \mathrm{C}$ & $600{ }^{\circ} \mathrm{C}$ & $800{ }^{\circ} \mathrm{C}$ \\
\hline $\begin{array}{l}\text { Elastic modulus, } \\
(\mathrm{GPa})\end{array}$ & 224.0 & 153.80 & 94.0 & 31.70 \\
\hline $\begin{array}{l}\text { Yield strength, } \sigma_{Y} \\
(\mathrm{MPa})\end{array}$ & 340.0 & 320.71 & 140.80 & 34.60 \\
\hline $\begin{array}{l}\text { Ultimate tensile } \\
\text { strength, } \sigma_{T}(\mathrm{MPa})\end{array}$ & 546.20 & 498.60 & 185.50 & 61.20 \\
\hline $\begin{array}{l}\text { Fracture strain } \\
\text { (elongation), } \varepsilon_{f}\end{array}$ & 0.30 & 0.37 & 0.61 & 1.08 \\
\hline
\end{tabular}

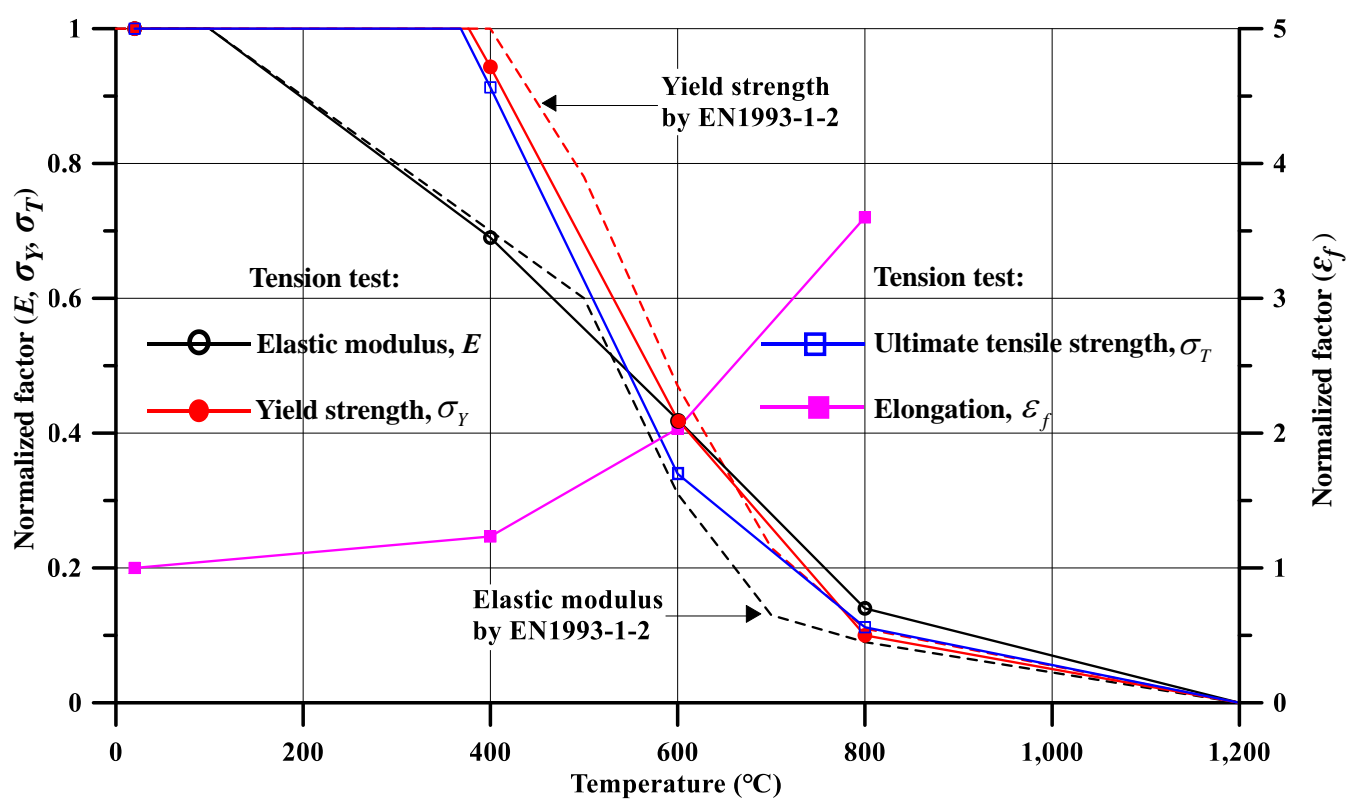




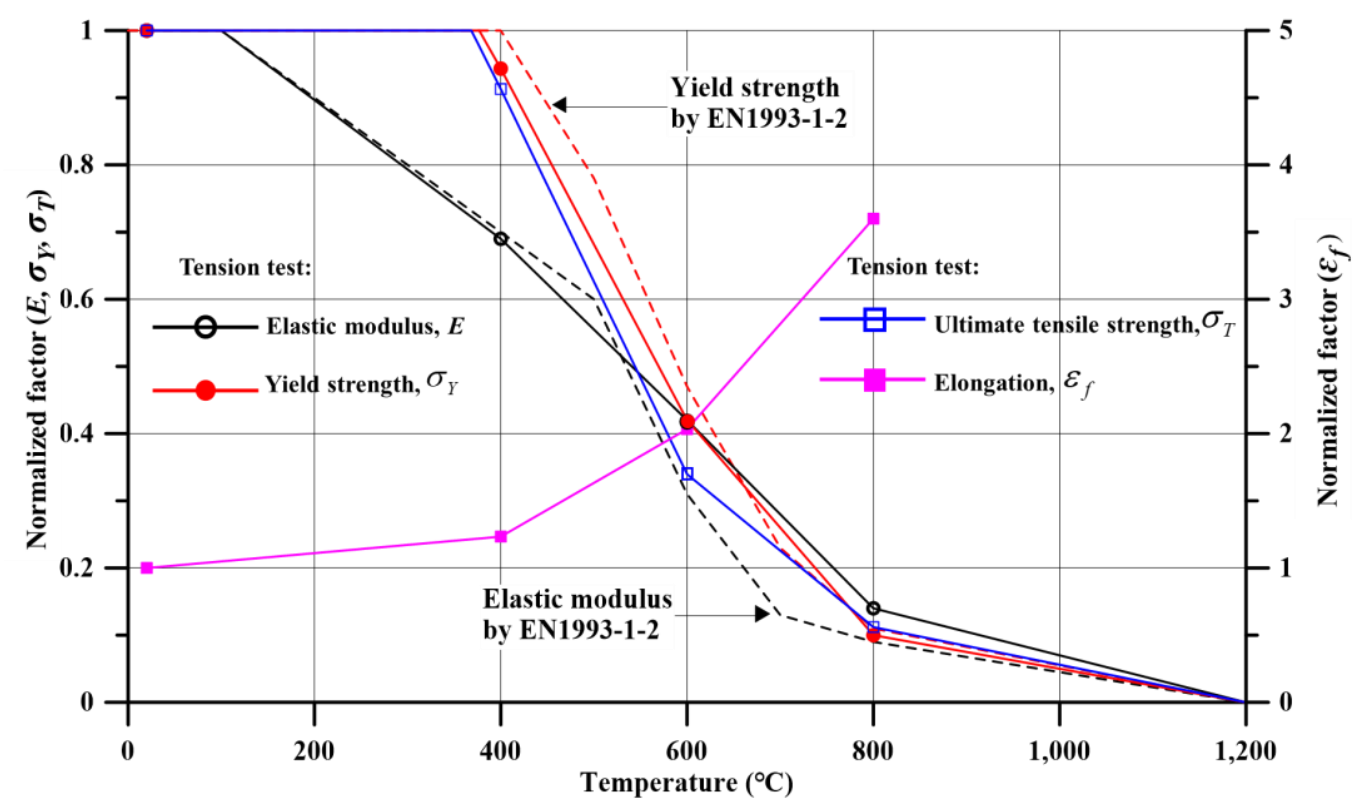

Figure 8. Comparison of material properties between tension tests and EN 1993-1-2 for AH32 high tensile steel.

\section{Fabrication of the test structure}

The test structure was fabricated at a shipyard in Busan, South Korea using exactly the same welding technology as used in today's shipbuilding industry. The shipyard has built small and medium sized merchant and patrol ships. The aim of building the test structure at a shipyard was to attain the same conditions of flaming cutting and welding as for real ship structures.

Table 4. Welding conditions applied for the fabrication of the test structure.

\begin{tabular}{|l|l|}
\hline Method & FCAW \\
\hline Flux-cored wire & CSF-71S \\
\hline Leg length & $7 \mathrm{~mm}$ \\
\hline Current & $260 \mathrm{~A}(225 \sim 275 \mathrm{~A})$ \\
\hline Voltage & $28 \mathrm{~V}(23 \sim 32 \mathrm{~V})$ \\
\hline Welding speed & $30 \mathrm{~cm} / \mathrm{min}(24 \sim 34 \mathrm{~cm} / \mathrm{min})$ \\
\hline Heat input & $14.56 \mathrm{KJ} / \mathrm{cm}(7 \sim 18 \mathrm{KJ} / \mathrm{cm})$ \\
\hline
\end{tabular}

Note: The value in the parenthesis indicates the welding procedure specification requirements.

Table 4 summarises the welding conditions applied for fabricating the test structure. To minimise welding-induced initial imperfections, the plating of the test structure was entirely made of an identical steel sheet by avoiding butt welds to connect pieces of steel sheets. All longitudinal stiffeners and transverse frames were attached by continuous fillet welding following the welding requirements of DNV GL (2018). The flux-cored arc welding (FCAW) method was applied. Figure 9 shows a flow of the fabrication process. 
Support jigs were welded to the test structure along its four edges as shown in Figure 10. The test structure was transported from the shipyard to the test site at ICASS/KOSORI (www.icass.center) in Hadong, South Korea.

(a)

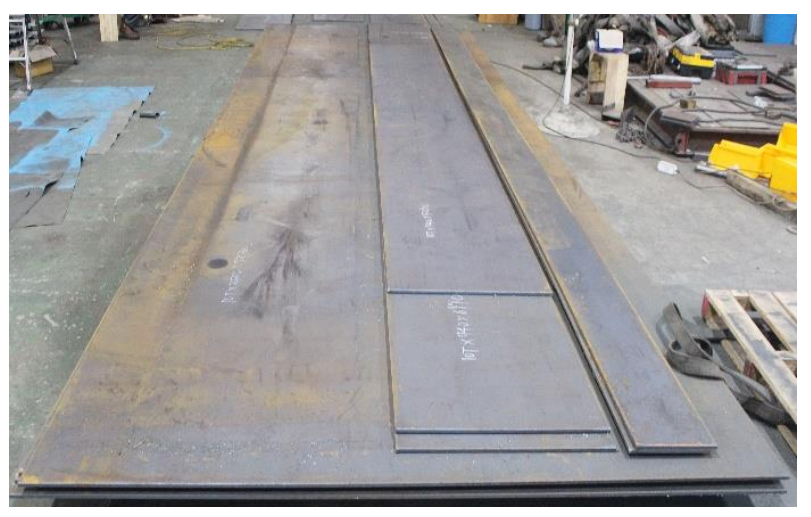

(b)
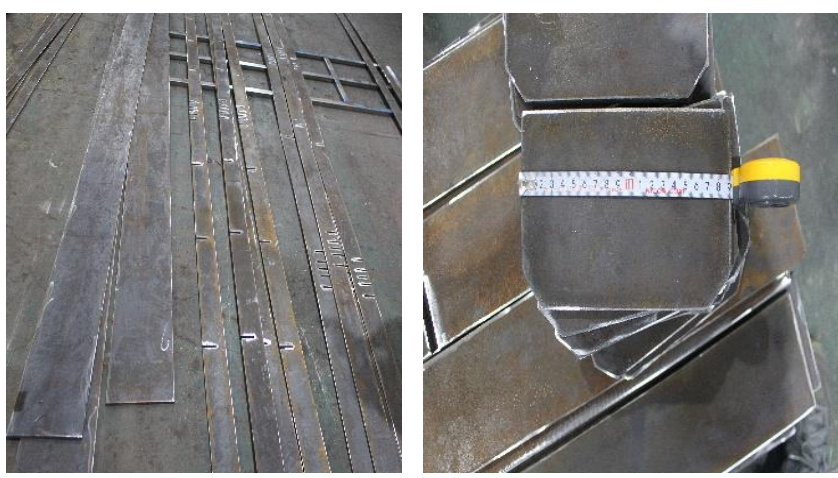

(c)
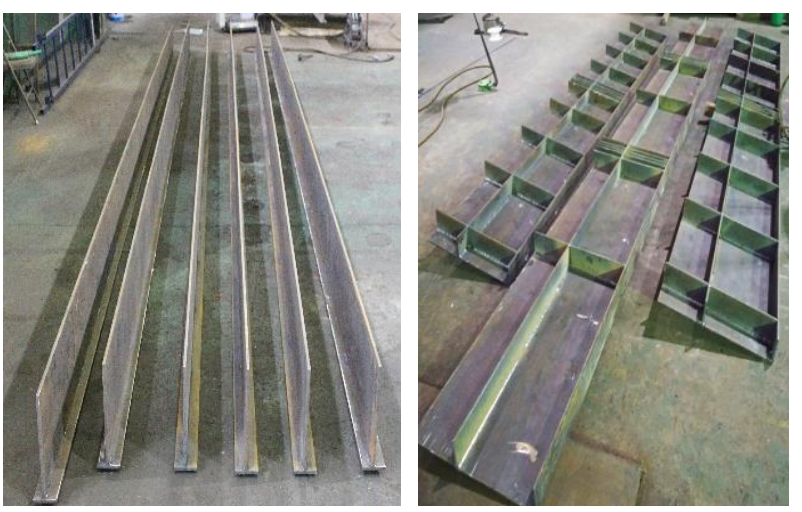
(d)

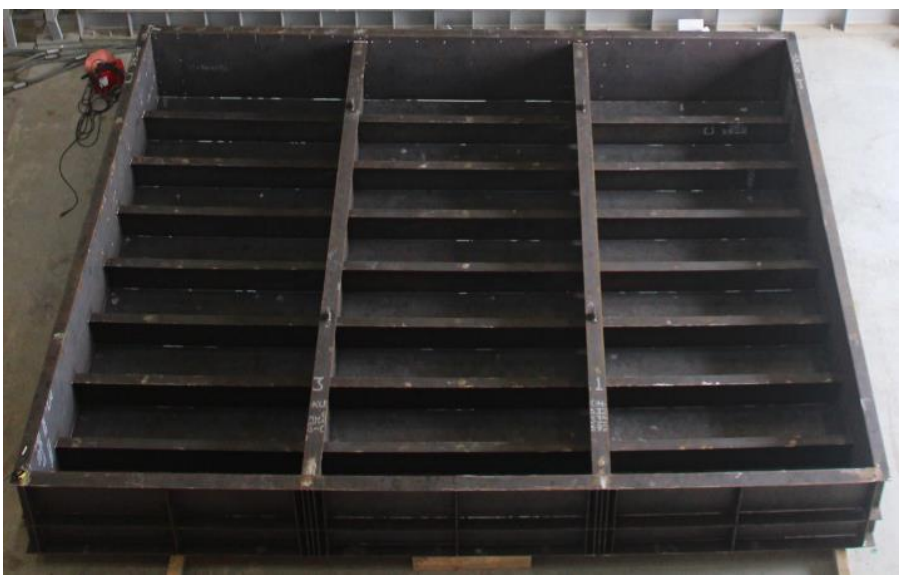

Figure 9. The fabrication process at the shipyard: (a) raw plate sheet, (b) plate cutting, (c) assembly of support members and support jigs, (d) completion of the test structure.

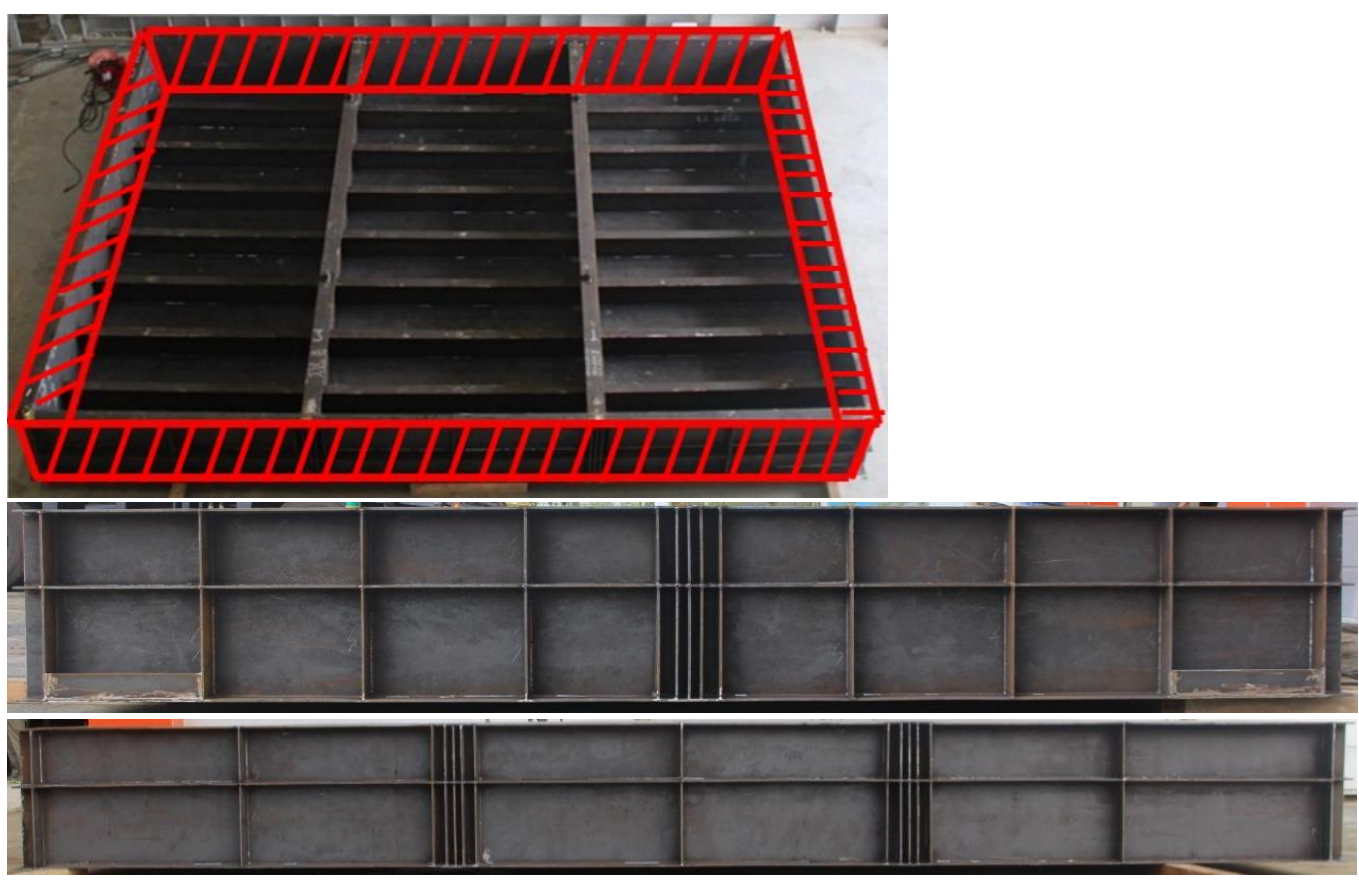

Figure 10. Fabrication of support jigs along four boundaries of the test structure.

During the process of welding fabrication, initial imperfections are inevitably developed in the form of initial deflections and residual stresses which can significantly affect the ultimate strength under predominantly axial compressive loading (Paik 2018). However, the test structure under consideration in the paper is subjected to lateral patch loading at elevated temperatures, and the effects of initial imperfections on the structural collapse in fires are considered to be very small. In this regard, the welding-induced initial imperfections were not measured.

In parallel, the authors' group conducted full-scale physical tests on the ultimate compressive strength of steel stiffened plate structures under cyclic compressive loading (Paik et al. 2020a) or triggered by brittle fracture at cryogenic condition associated with an accidental scenario of unwanted LNG (liquefied natural gas) release (Paik et al. 2020b). 
Similar test structures in size and shape to the present test structure in association with plate panels of the 1,900 TEU containership were built at the same shipyard during the same period using the same welding technology. Welding-induced initial imperfections of test structures were measured using modern technologies such as a three-dimensional scanner of structural geometry and an X-ray detector of residual stresses. Details of their measurement data are presented in Yi et al. (2020a, 2020b).

\section{Test set-up}

The testing was conducted in a horizontal type furnace at the test site of the ICASS/KOSORI in Hadong, South Korea (www.icass.center). Figure 11 shows this type fire furnace test facility. The space inside the furnace is $6,500 \mathrm{~mm}$ long, 4,500 $\mathrm{mm}$ wide and $1,730 \mathrm{~mm}$ deep. The test structure was positioned horizontally to cover up on top of the furnace, while burners supplied by liquefied petroleum gases were used to raise ambient temperature inside the furnace. The maximum gas cloud temperature that can be applied in the test facility is $1,430{ }^{\circ} \mathrm{C}$. Figure 12 shows a target curve of increasing gas cloud temperatures with time as per the ISO 834 fire curve (ISO 834 1999), which presents a guideline of predicting the time history of ambient temperatures for engineering structures in fires. It can be expressed in the following equation:

$$
T=20+345 \log (8 t+1)
$$

where $T$ is the gas cloud temperature in ${ }^{\circ} \mathrm{C}$ and $t$ is the time in minute. Figure 12 also shows the ISO 834 curve $15 \%$ below the original curve, which was applied for the present test.

The test structure was set up as a top cover of the furnace where the side of support members such as transverse frames and longitudinal stiffeners was located inside the furnace. The support jigs of the test structure were welded to the framework of the furnace to prevent the whole test structure from moving in the horizontal direction. At 12 locations as shown in Figure 13, a $300 \mathrm{~mm}$ long welding of a supporting jig was applied along part of the furnace boundary as shown in Figure 14. For nonlinear finite element modelling of the structural framework, a fixed boundary condition may be approximately applicable.

The boundaries of the furnace should be fully shielded to prevent elevated temperatures inside the furnace from flowing outside the test structure, and thus all the four boundaries were insulated by fire protection material, called cerawool, which can achieve an ultra-high temperature-resistant and fireproof condition by lowering thermal conductivity with melted and fiberised high purity silica (sand) and alumina. Table 5 and Figure 15 present the nominal values for the properties of cerawool (DIFK 2014). Figure 16 shows the insulation with fire protection material along the four edges of the test structure. Figure 17 shows the completion of the test set-up including loading and sensors of test data acquisition that will be described later. 


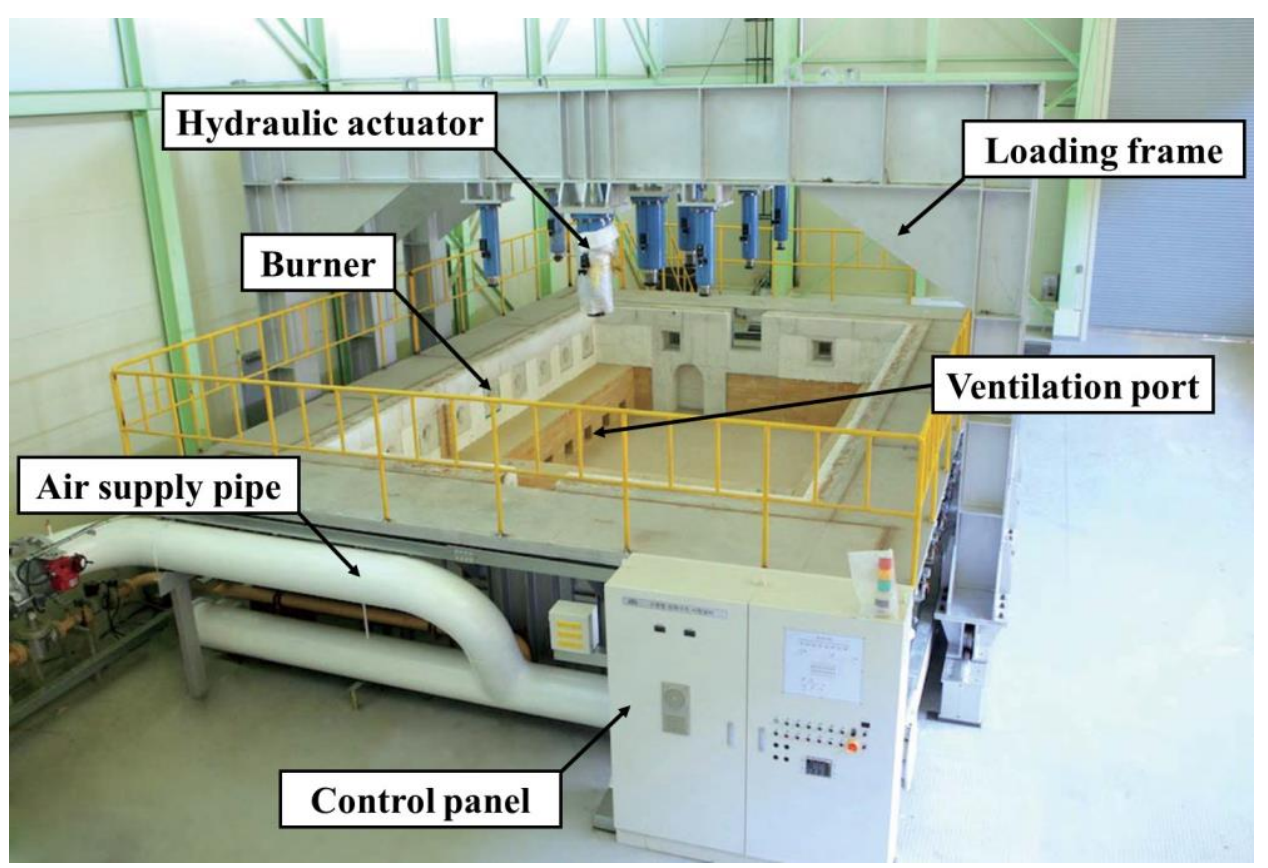

Figure 11. Horizontal type fire test furnace facility of the ICASS/KOSORI in Hadong, South Korea.

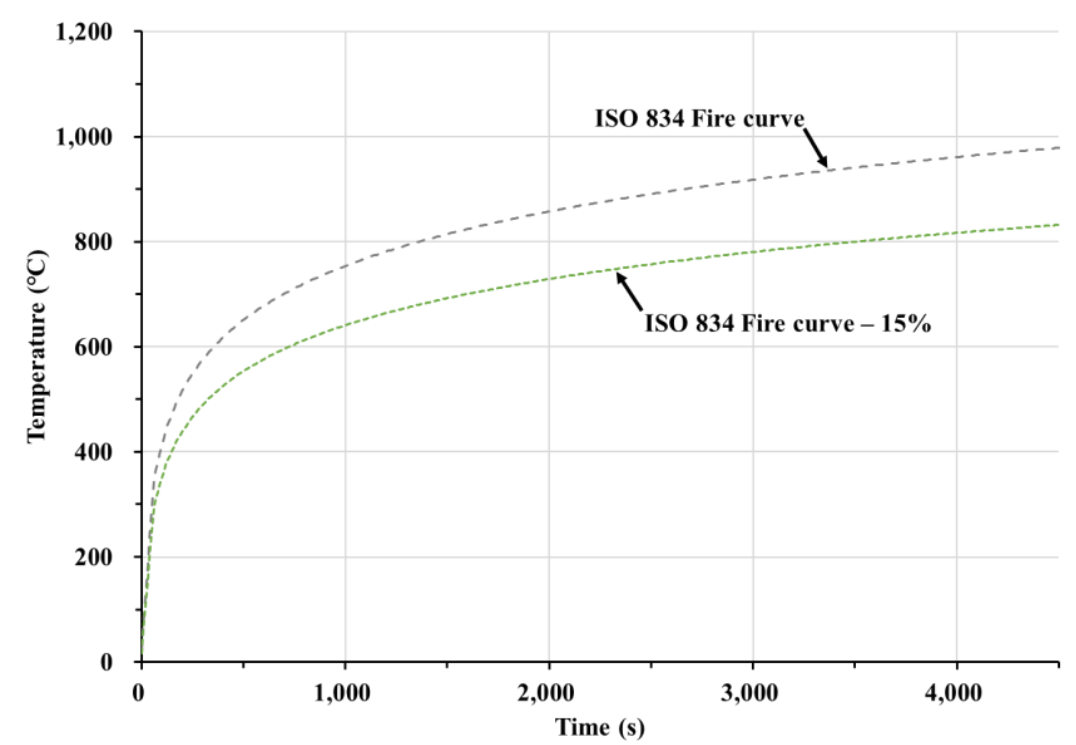

Figure 12. A target curve of increasing temperatures with time as per the ISO 834 fire curve. 


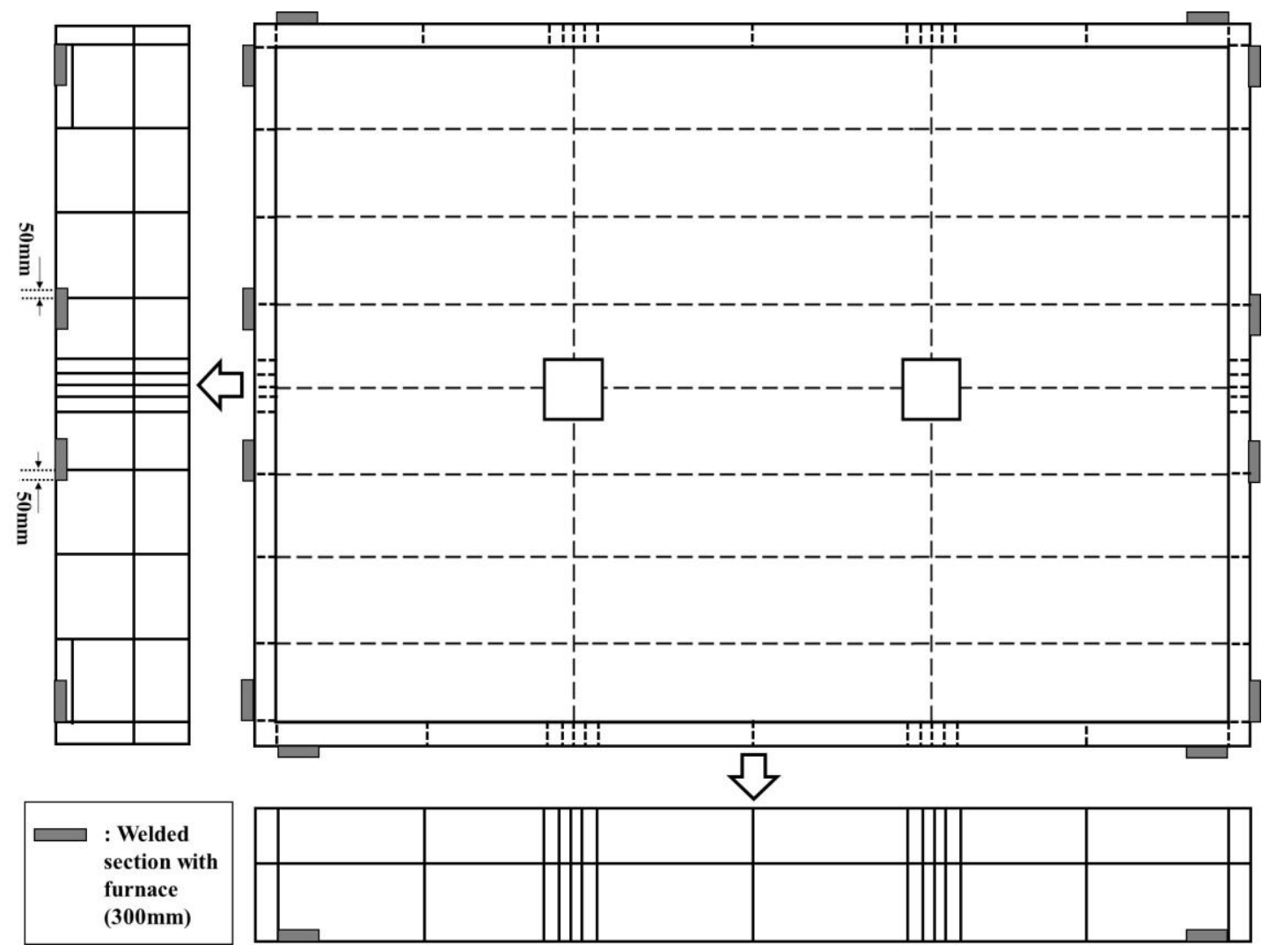

Figure 13. Plan and profile views showing the welded locations between supporting jigs and the furnace.

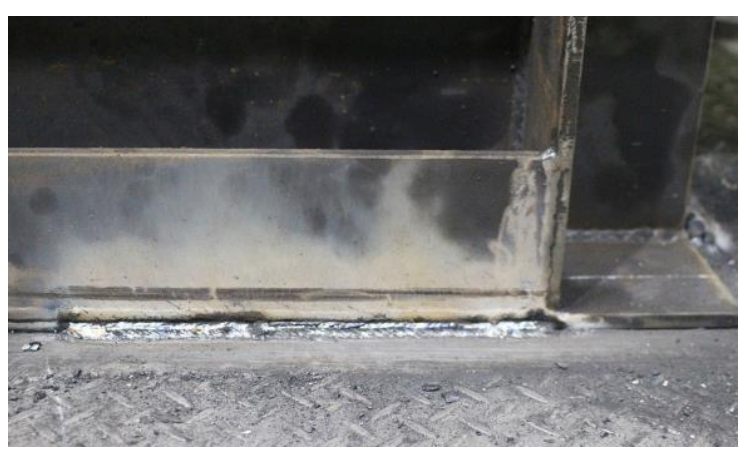

Figure 14. A $300 \mathrm{~mm}$ long welding of a supporting jig along part of the furnace boundary.

Table 5. Nominal properties of cerawool (DIFK 2014).

\begin{tabular}{|l|l|l|l|l|}
\hline Thickness & Tensile strength & Density & $\begin{array}{l}\text { Maximum service } \\
\text { temperature }\end{array}$ & Specific heat \\
\hline $50 \mathrm{~mm}$ & $0.750 \mathrm{MPa}$ & $0.128 \mathrm{ton} / \mathrm{m}^{3}$ & $1,200^{\circ} \mathrm{C}$ & $2,550 \mathrm{~J} / \mathrm{Kg}{ }^{\circ} \mathrm{C}$ \\
\hline
\end{tabular}




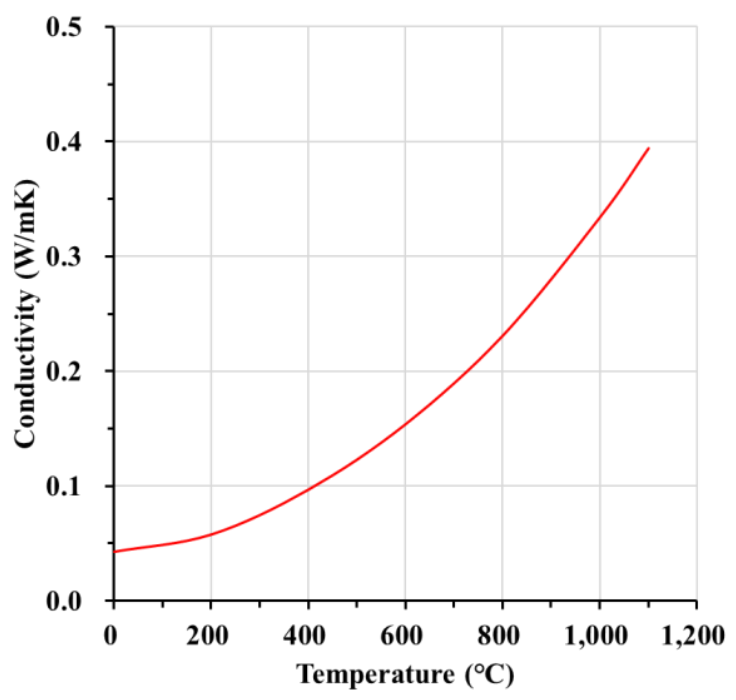

Figure 15. Thermal conductivity of cerawool (DIFK 2014).
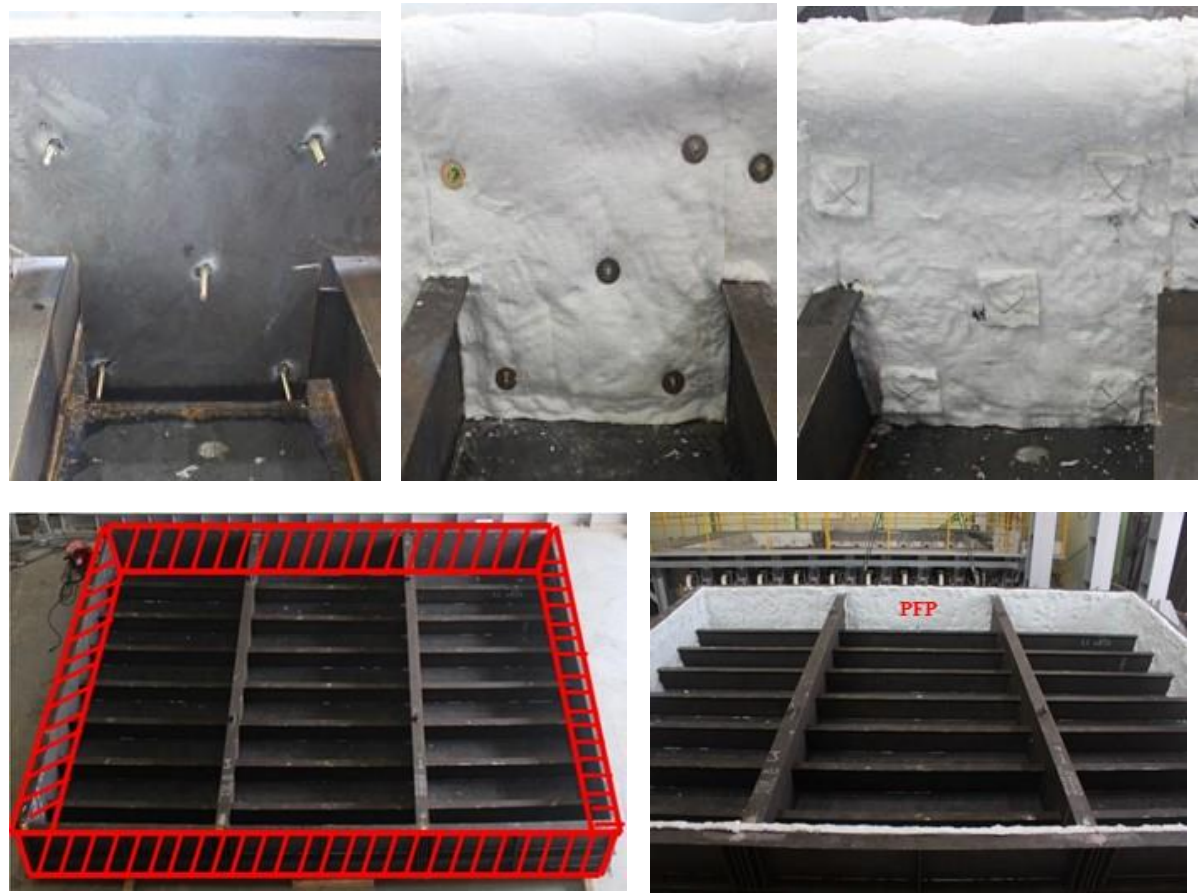

Figure 16. Insulation with passive fire protection material along the four boundaries of the test structure. 


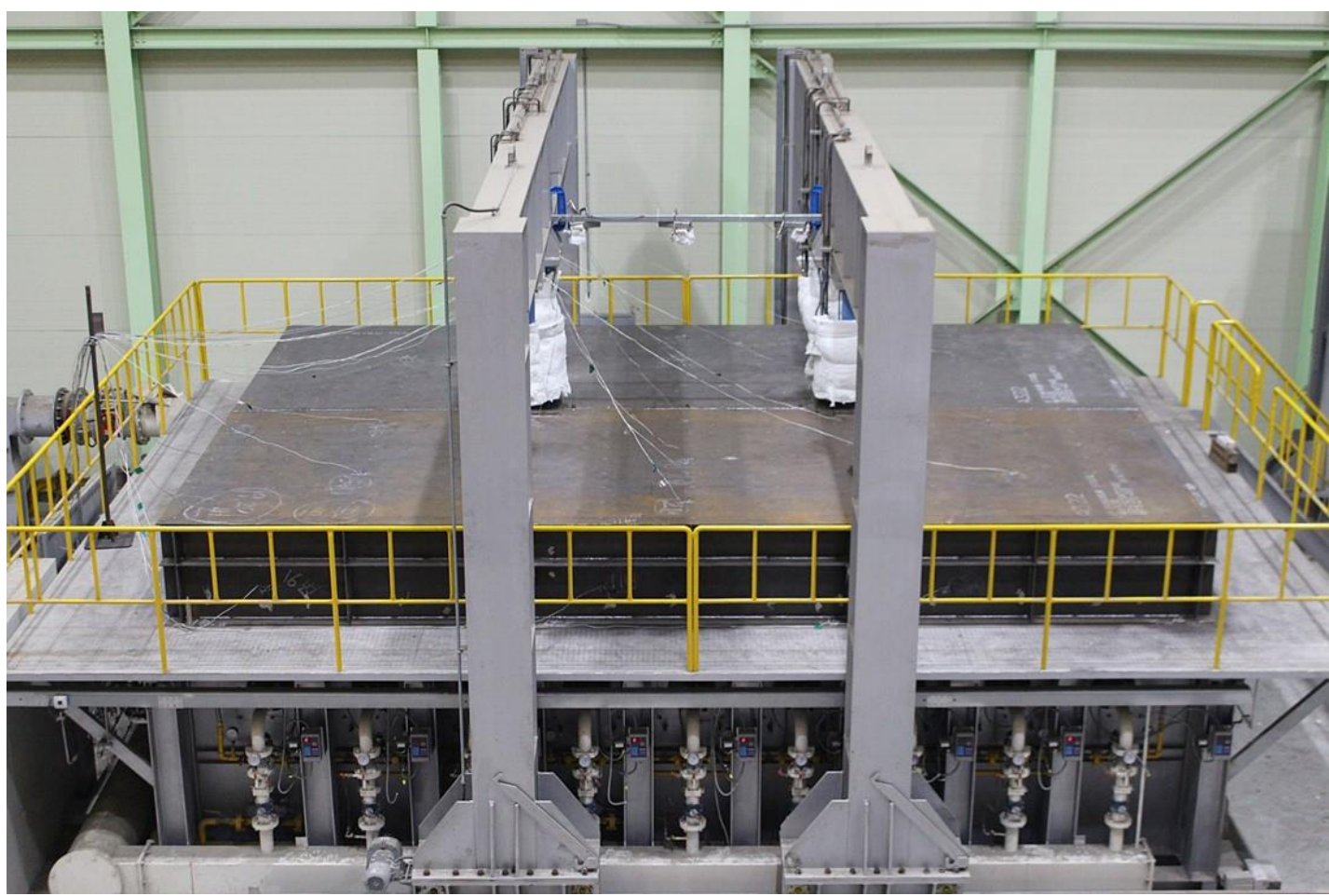

Figure 17. Completion of the test set-up at the test site

\section{Lateral patch loading}

Three hydraulic loading actuators are accommodated in the test facility to apply external forces up to $100 \mathrm{tf}$ (tonne-force) by each actuator. The test program associated with temperature and external loading is monitored and controlled by a computer system in the control room, which is located at an elevation to view the overall test scene away from the furnace. Physical databases such as loads and temperatures (gas cloud and steel) are recorded at a time interval of several seconds (e.g., 10 seconds).

Two out of the three hydraulic loading actuators were used for the tests, where lateral patch loads were applied at the centre of each transverse frame as shown in Figure 18. Multiple layered steel plates including one plate insulated with passive fire protection were inserted between the loading actuator tip and the patch area of the test structure, as shown in Figures 19 and 20, to apply the patch loads uniformly over the patch area and also to protect loading actuators from heat. To prevent the transfer of high temperature from the heated test structure to the loading actuators, which may cause a malfunction, they were insulated by fire protection material with cerawool as shown in Figure 21. 


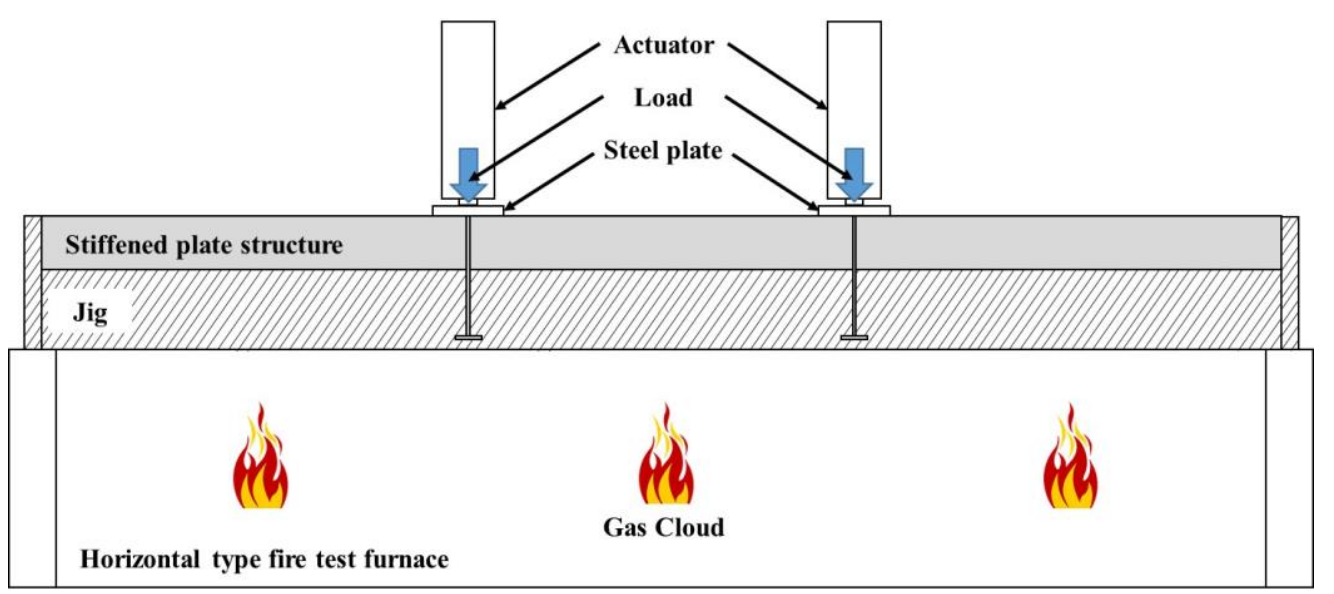

Figure 18. Set-up for applying lateral patch loads at the centre of transverse frames.

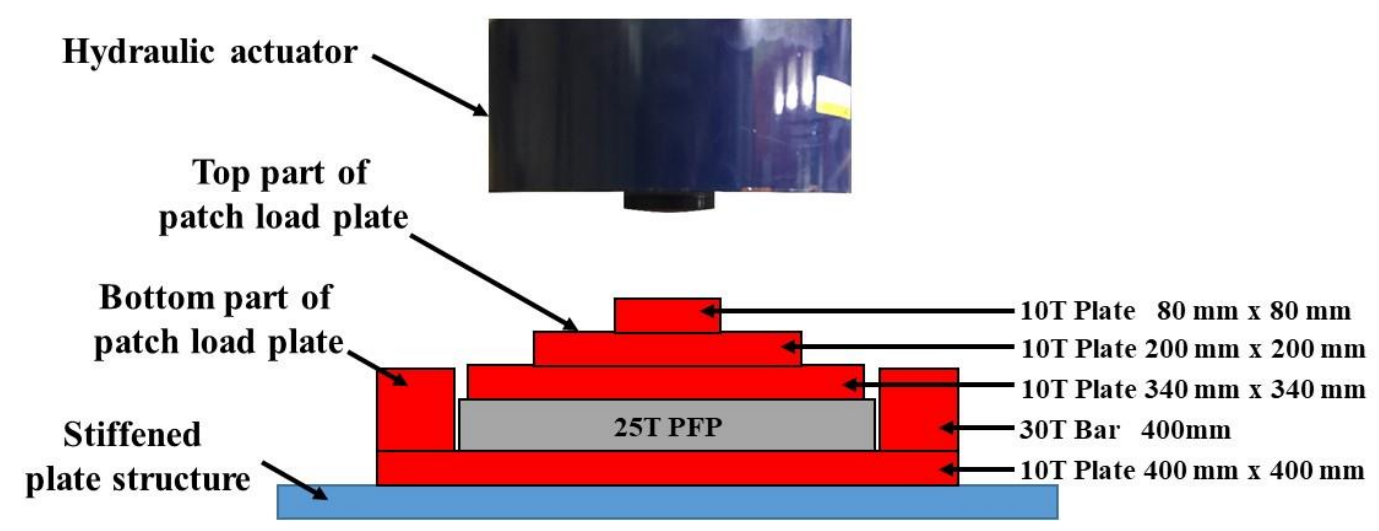

Figure 19. Multiple layered steel plates between the loading actuator and the patch loading area (side view).
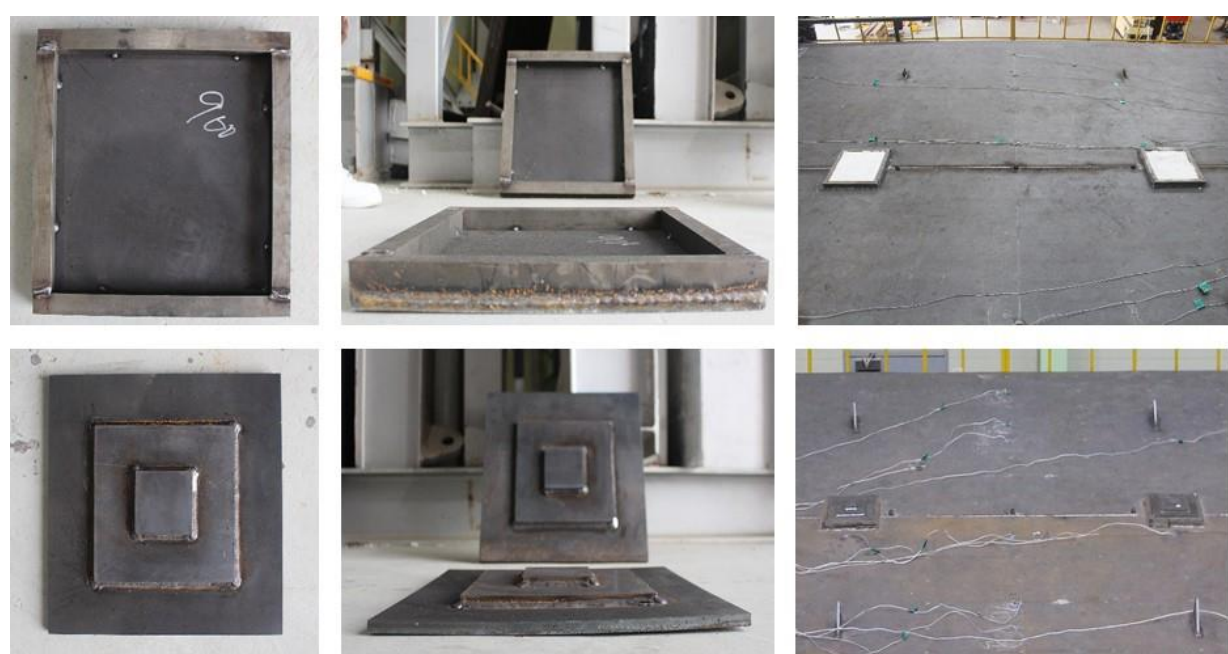

Figure 20. Manufactured and installed patch load plates. 


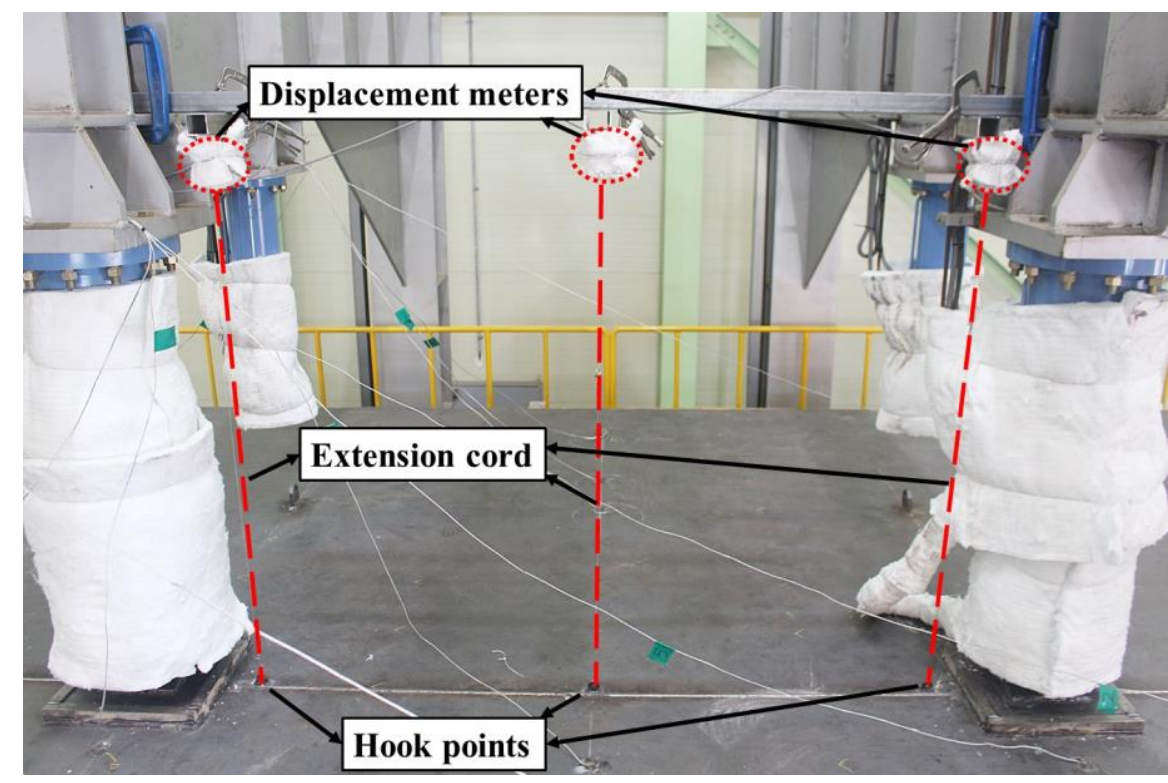

Figure 18. Insulation of passive fire protection for loading actuators to prevent them from heat transfer.

Lateral patch loads were applied in two steps as shown in Figure 22, where $15 \mathrm{tf}$ were applied at each loading point and maintained for 1,580 seconds in the first step, and $50 \mathrm{tf}$ were applied at each loading point after fully unloading of the first load step at 1,630 seconds and maintained until the test ended by structural collapse at 2,630 seconds. At each loading step, the magnitude of load application was kept constant, where the stroke of hydraulic loading actuator was automatically controlled so that the applied loading was considered as a "dead load". A computer system in the control room was used for this purpose.

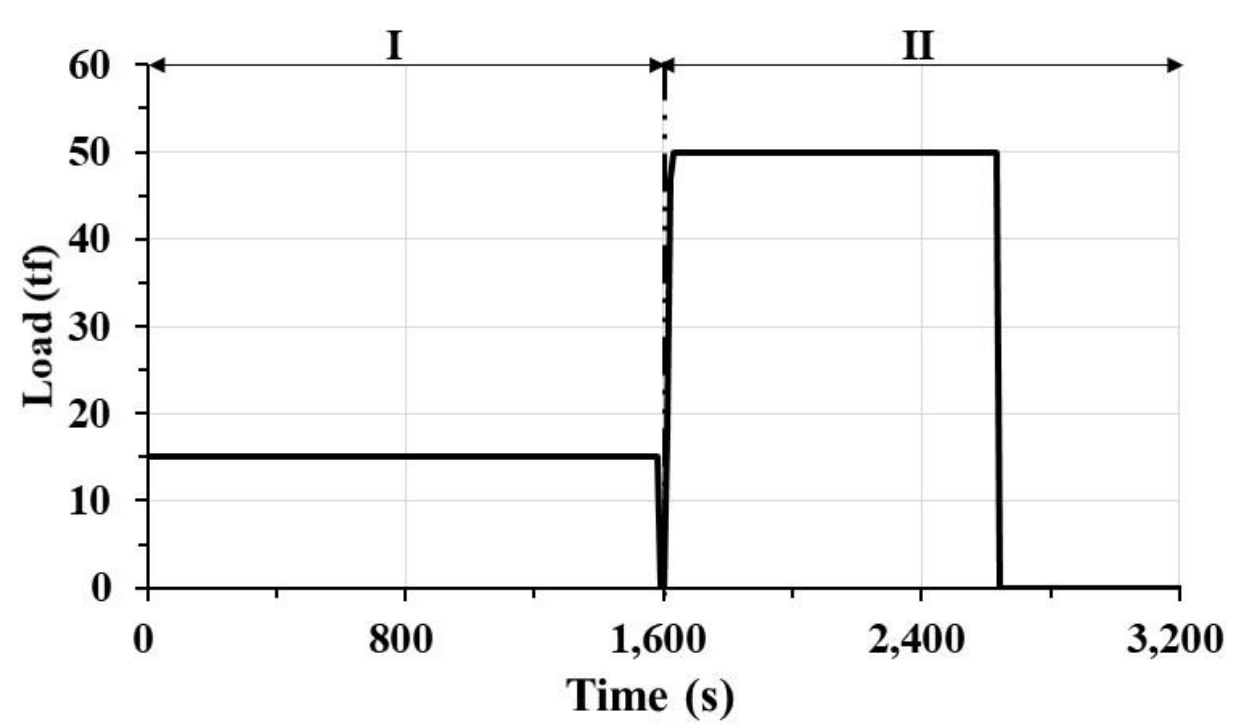

Figure 22. Measured profile of lateral patch loads at two steps associated with each loading actuator. 


\section{Test data acquisition}

Table 6 indicates details of thermos-electric couple sensors and displacement meters used for test data acquisition, where their precision of measurements was calibrated and accredited by KOLAS (Korea Laboratory Accreditation Scheme) in association with ILAC (International Laboratory Accreditation Cooperation). On the other hand, applied loads were measured by load cells located at the tip of each loading actuator.

Table 6. Manufacturers and models of sensors and meters used for test data acquisition.

\begin{tabular}{|c|c|c|c|c|c|}
\hline Test data & Instrument & Manufacturer & Model & $\begin{array}{l}\text { Applied } \\
\text { sampling } \\
\text { rate }\end{array}$ & Remark \\
\hline $\begin{array}{l}\text { Gas cloud } \\
\text { temperature }\end{array}$ & $\begin{array}{l}\text { Thermo-electric } \\
\text { couple sensor }\end{array}$ & $\begin{array}{l}\text { Intelligent } \\
\text { Sensor Line } \\
\text { Co., Ltd., } \\
\text { South Korea }\end{array}$ & K-type & $\begin{array}{l}10 \\
\text { seconds }\end{array}$ & \multirow{2}{*}{$\begin{array}{l}\text { Temperature } \\
\text { range of }-270{ }^{\circ} \mathrm{C} \\
\text { to } 1,260{ }^{\circ} \mathrm{C} \text {. Well } \\
\text { suited to } \\
\text { oxidizing } \\
\text { atmospheres. }\end{array}$} \\
\hline $\begin{array}{l}\text { Steel } \\
\text { temperature }\end{array}$ & $\begin{array}{l}\text { Thermo-electric } \\
\text { couple sensor }\end{array}$ & $\begin{array}{l}\text { Haedong Co., } \\
\text { Ltd., South } \\
\text { Korea }\end{array}$ & K-type & $\begin{array}{l}10 \\
\text { seconds }\end{array}$ & \\
\hline $\begin{array}{l}\text { Lateral } \\
\text { deformation }\end{array}$ & $\begin{array}{l}\text { Displacement } \\
\text { meter }\end{array}$ & $\begin{array}{l}\text { A-Best Co., } \\
\text { Ltd., South } \\
\text { Korea }\end{array}$ & CDM-1000 & 1 second & $\begin{array}{l}\text { Maximum } 1,000 \\
\mathrm{~mm} \text { in a } \\
\text { temperature } \\
\text { range of }-20{ }^{\circ} \mathrm{C} \\
\text { to } 60^{\circ} \mathrm{C}\end{array}$ \\
\hline
\end{tabular}

\subsection{Gas cloud temperatures}

The time history of the gas cloud temperatures inside the furnace was measured at a time interval of 10 seconds using thermo-electric couple sensors wired to the personal computer in the control room. A total of 14 points inside the furnace as shown in Figure 23 were used to measure gas cloud temperatures. The sensors were positioned $300 \mathrm{~mm}$ below the test structure with two arrays on each side.
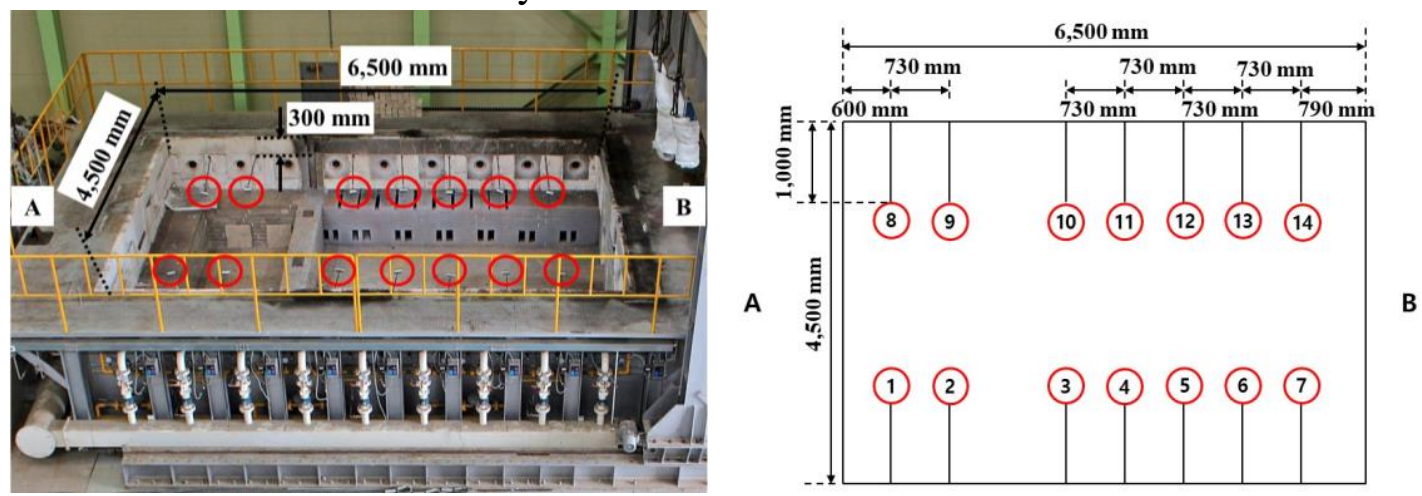

Figure 23. A total of 14 monitoring points to measure gas cloud temperatures inside the furnace. 


\subsection{Steel temperatures}

Gas cloud temperatures were transferred to the steel structure, and the time history of the steel temperatures of the test structure was measured at a time interval of 10 seconds for 14 monitoring points (Nos. 1-13 and 21) using the thermo-electric couple sensors which are a different model from those used to measure gas cloud temperatures as indicated in Table 6. Also, a total of 7 locations (Nos. 14-20) were monitored to measure steel temperatures of supporting jigs insulated by fire protection materials, which could be used to assess their support effectiveness against fires. The sensors Nos. 1-20 were allocated to measure steel temperatures at plating of the test structure outside the furnace. On the other hand, one sensor (No. 21) was used to measure steel temperatures of the test structure inside the furnace. Figure 24 shows the locations of the monitoring points to measure steel temperatures. The thermos-electric sensors were attached by spot welding to avoid the detachment at very high temperatures, as shown in Figure 25.

To attach a sensor (No. 21) for measuring steel temperatures inside the furnace, a hole with a diameter of $6 \mathrm{~mm}$ was made at the centre of the test structure to pass wire through. Two dummy steel plates with a size of $200 \mathrm{~mm} \times 290 \mathrm{~mm}$ were attached to the test structure inside the furnace, and they were placed in overlap with a thickness of $5 \mathrm{~mm}$ together with a ceramic tube with a diameter of $4 \mathrm{~mm}$, which is enough to pass the insulated wire of the sensor through. Figure 26 shows the design of the dummy steel plates, and Figure 27 shows the installation of the sensor into the dummy steel plates.

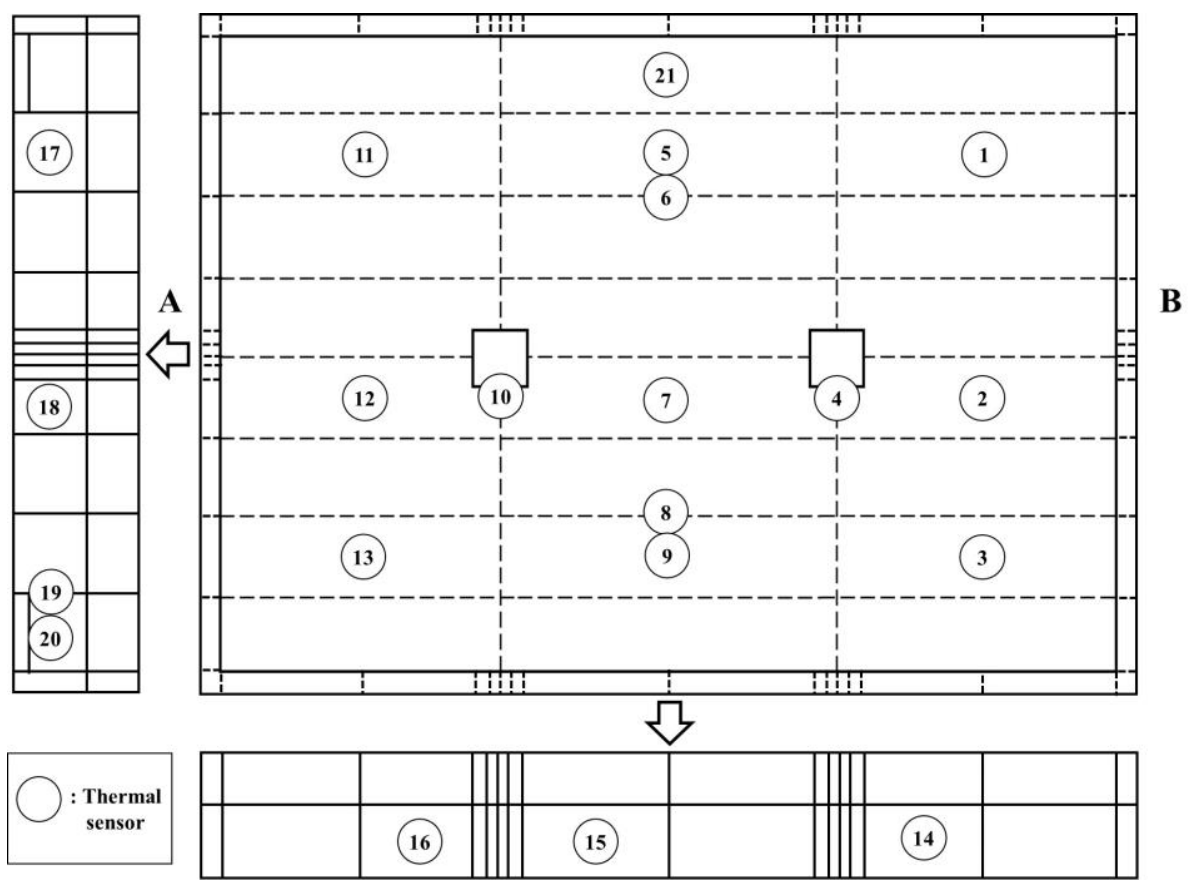

Figure 24. Locations of the 20 monitoring points to measure steel temperatures (top view). 


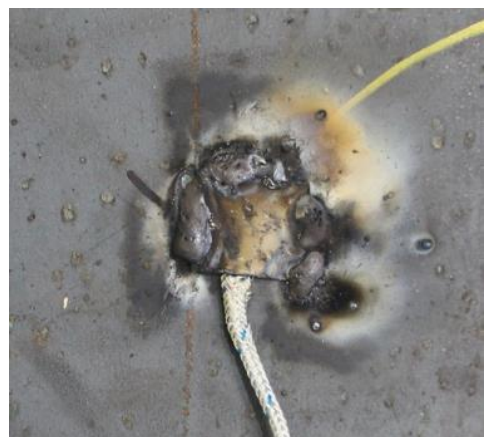

Figure 25. Spot welding to attach thermo-electric couple sensors.

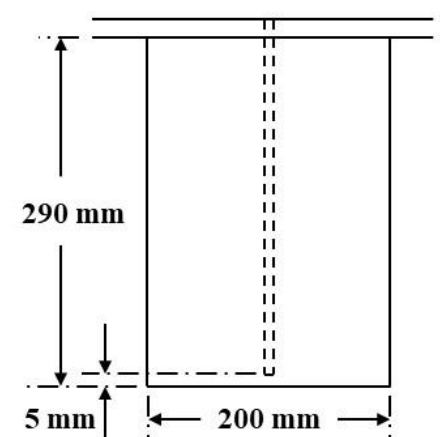

[Front view]

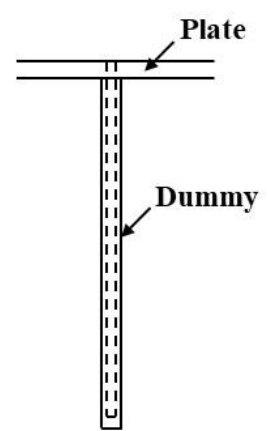

[Side view]

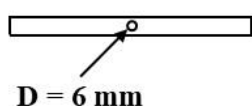

[Top view]

Figure 26. Design of the dummy steel plates.
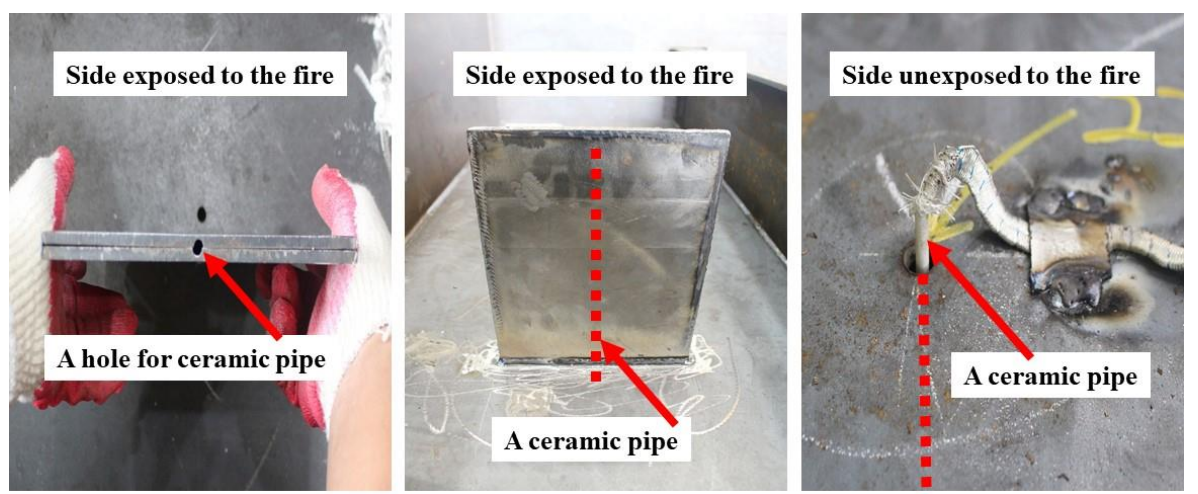

Figure 27. Installation of the sensor (No. 21) into the dummy steel plates.

\subsection{Lateral deflections}

Lateral patch loading was automatically controlled by the personal computer in the control room as a dead load after increasing up to the target value. This implies that the stroke of the loading actuator needed to maintain the same load despite the increase of lateral deformation. Also, the controller worked to secure the synchronising of the two loading at the same patch loads.

Lateral deformation continued to increase with time at elevated temperatures even if the applied loads were kept unchanged. The time history of lateral deformations was at a time 
interval of 1 second for three monitoring points using displacement meters as indicated in Table 6. Because of the loading actuators, two displacement meters were placed $300 \mathrm{~mm}$ away from the centre of the patch loading points, as shown in Figure 28, while the last displacement meter was positioned on exactly the central point of the test structure. Figure 21 shows the set-up of displacement meters at the three monitoring points.

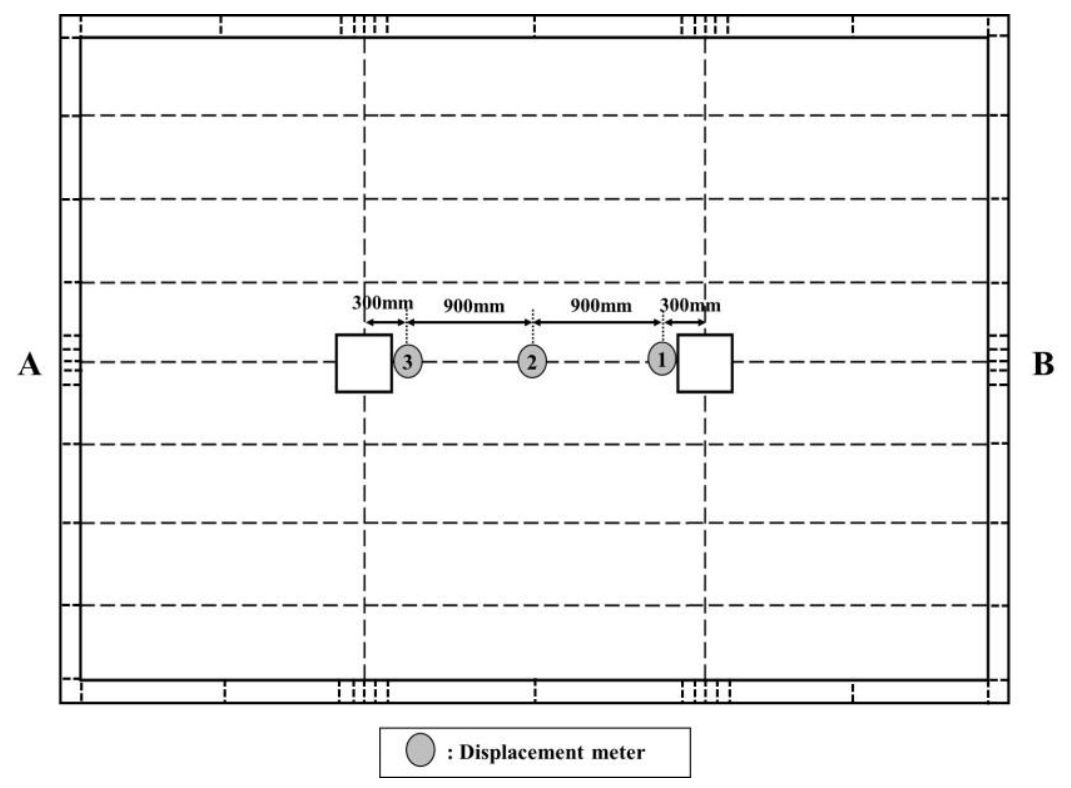

Figure 28. Locations of the three displacement meters.

\section{Test results and discussion}

\subsection{Gas cloud and ambient temperatures}

Figure 29 presents the change of ambient temperatures around the test structure outside the furnace. The room temperature was $27.6{ }^{\circ} \mathrm{C}$ before heating, and it was increased to $30.6^{\circ} \mathrm{C}$ after an hour, implying that the room temperature was almost constant.

Figure 30 presents the time history of the gas cloud temperatures measured at monitoring points inside the furnace. The average gas cloud temperature reached $600{ }^{\circ} \mathrm{C}$ at 180 seconds after the start of the gas burning, and it remained at $700-800{ }^{\circ} \mathrm{C}$ after 1,450 seconds, until the structure collapsed. From 2,720 seconds after the collapse of the structure, the temperature was drastically decreased as the gas burner was shut down.

Monitoring points 1, 7, 8 and 14 were located away from the centre of the test structure, and the gas cloud temperatures at these locations are slightly lower than other points close to the centre. However, it is proposed that the gas cloud temperatures are almost uniform inside the furnace. Figure 31 compares the time histories of the gas cloud temperatures between the measurements and the ISO 834 fire curve. It is seen from Figure 31 that the average gas cloud temperature is about $15 \%$ lower than the ISO 834 fire curve. 


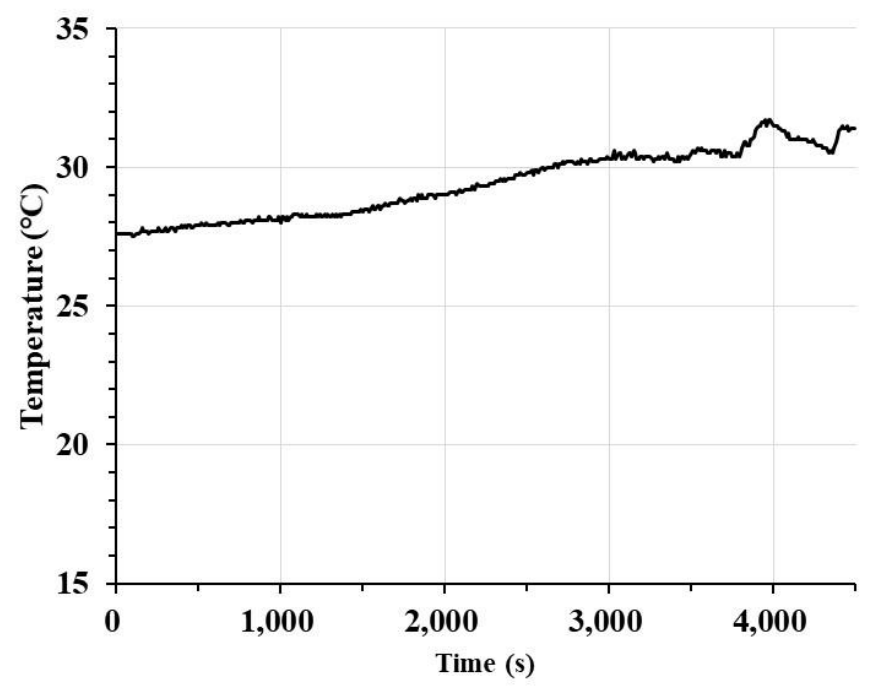

Figure 29. Ambient temperature outside the furnace around the test structure.
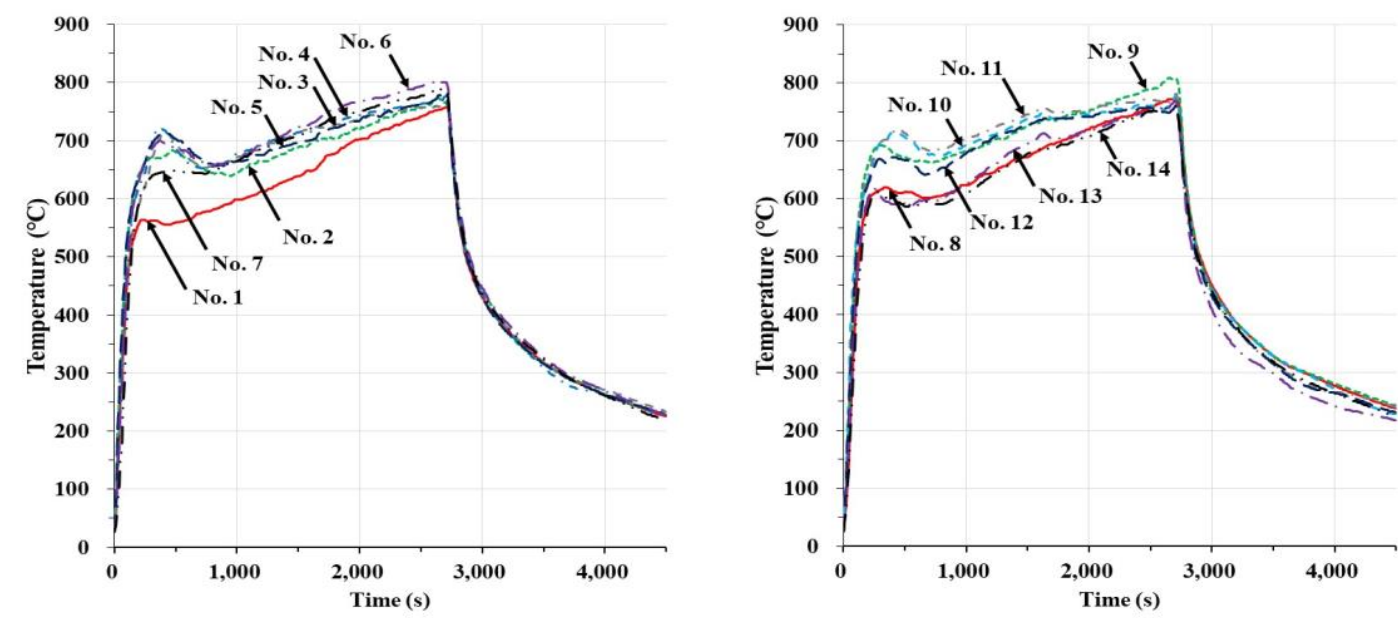

Figure 30. Gas cloud temperatures at monitoring points inside the furnace.

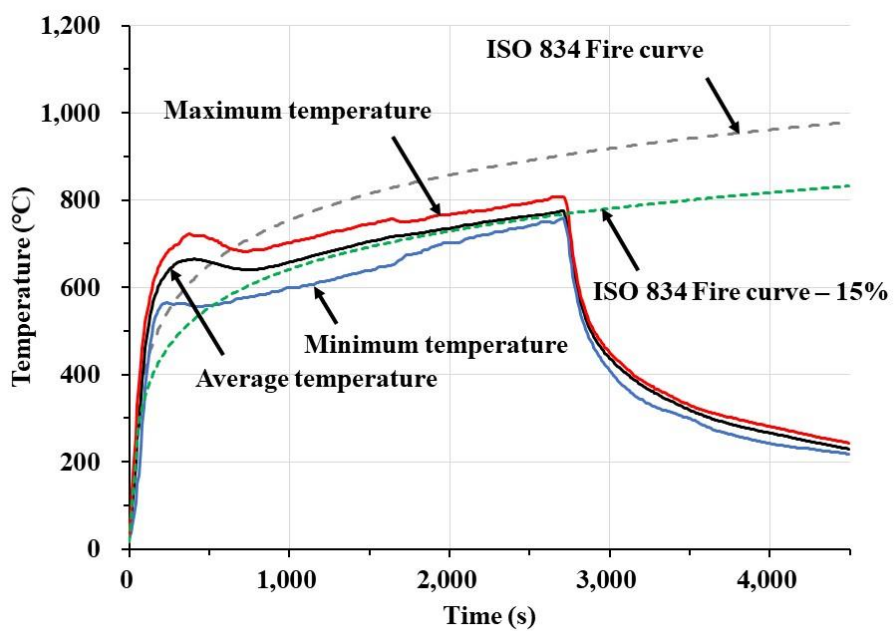

Figure 31. Comparison of gas cloud temperatures with the ISO 834 fire curve. 


\subsection{Steel temperatures}

Gas cloud temperatures are transferred to the steel structures. Figures 32(a)-(c) present steel temperatures measured at a total of 14 monitoring points of the test structure. Comparing steel temperatures in Figure 32 and gas cloud temperatures in Figure 30 reveals that the former is of course lower than the latter. Steel temperatures measured for supporting jigs are shown in Figure 32(d), showing that the maximum temperature is at most $94{ }^{\circ} \mathrm{C}$. This confirmed that the fire protection material almost fully insulated the supporting jigs and the fixed conditions along the boundaries of the test structure were secured.

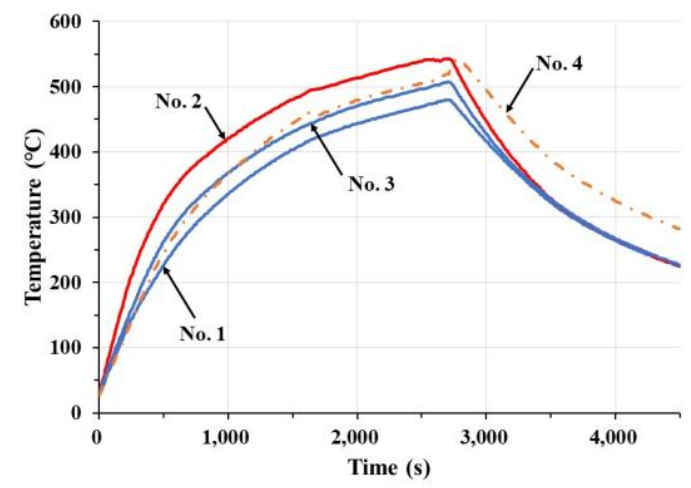

(a) Sensors 1 to 4

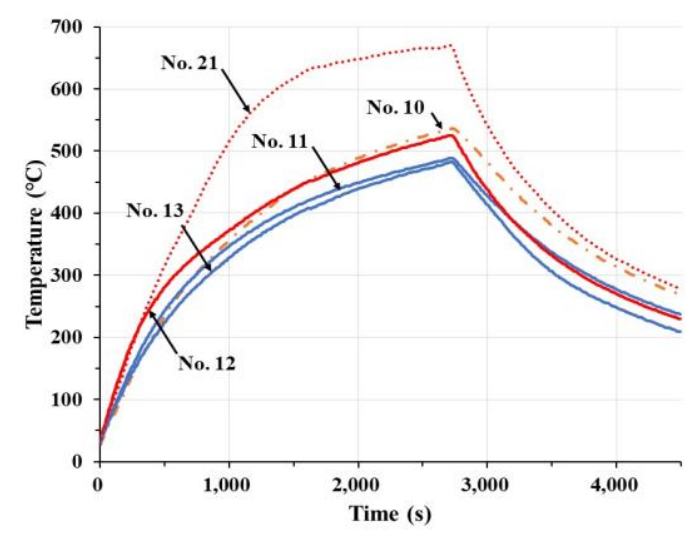

(c) Sensors 10 to 13 and 21

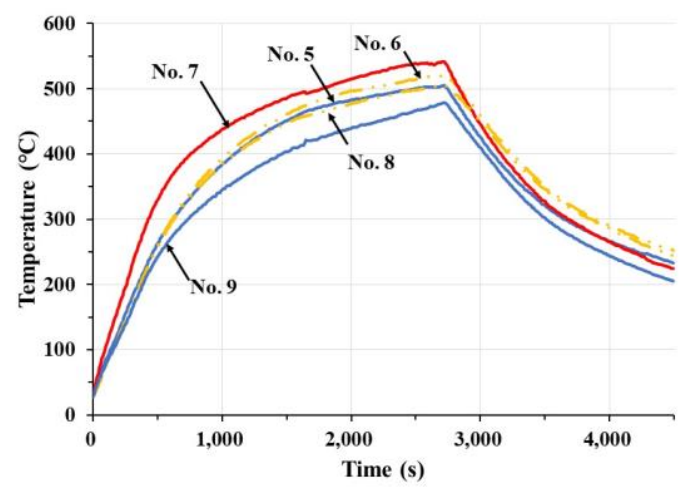

(b) Sensors 5 to 9

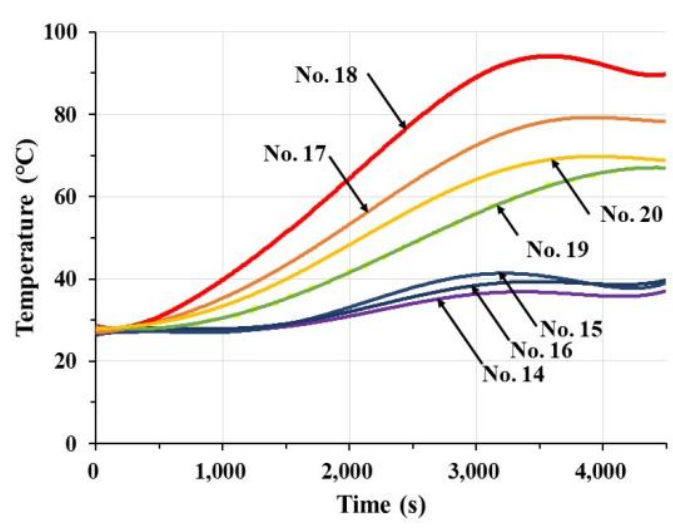

(d) Sensors 14 to 20

Figure 32. Steel temperatures measured at the monitoring points. 

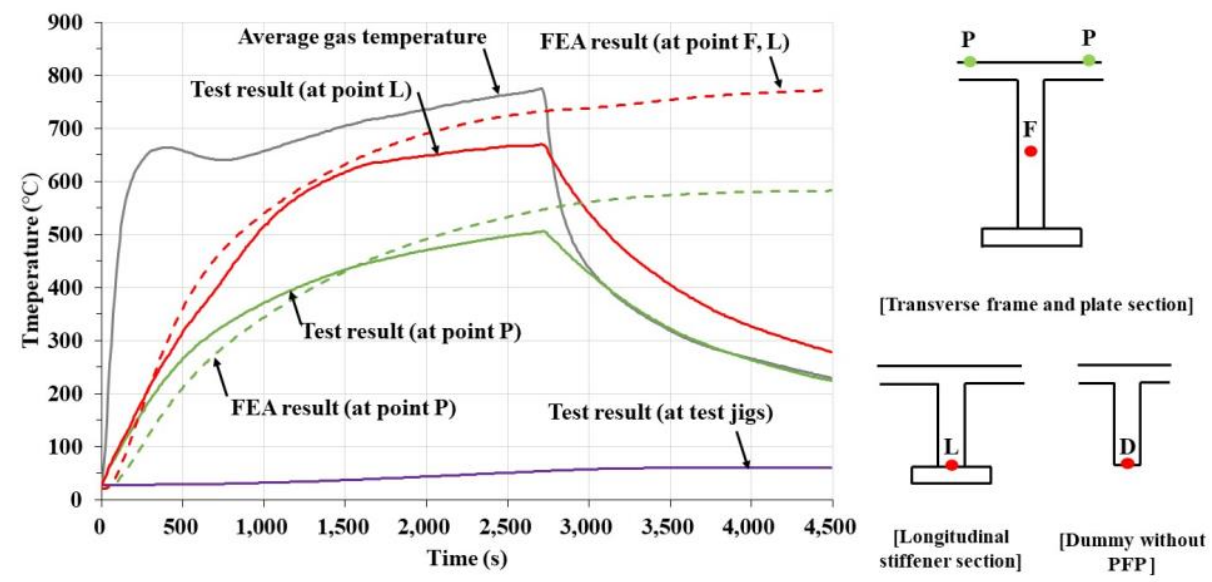

Figure 33. Comparison of steel temperatures between the measurements and the finite element method calculations by heat transfer analysis.

It is recognised that the heat transfer analysis using the finite element method is useful to predict steel temperatures, refer to Chapter 12 of Paik (2019). Figure 33 shows a comparison of steel temperatures between the measurements and the predictions, while details of the heat transfer analysis are presented in a separate paper (Ryu et al. 2020). It is seen from Figure 33 that the heat transfer analysis is in a good agreement with the measurements until 2,710 seconds when the gas burner was shut down as the structure entirely collapsed.

\subsection{Structural collapse}

The fire collapse behaviour of the test structure was monitored in association with the gas cloud temperatures and lateral deformations. Figure 34 presents the time history of the lateral deformations at three monitoring points where channel 1 and channel 3 indicate displacement meters close to the locations of patch loading and channel 2 is the displacement meter at the centre of the test structure. Until 1,600 seconds, almost no lateral deformations occurred under a patch load of $15 \mathrm{tf}$.

The lateral deformations increased dramatically at 1,630 seconds when a load of $50 \mathrm{tf}$ was applied at the start of the second load step. The lateral deformations were released at 2,550 seconds when the applied loads were removed. As far as the present schemes of loading and gas cloud temperatures are considered, the critical period of time until the test structure reaches the entire collapse is 1,600 seconds.

The Appendix provides the time history of the lateral deformation obtained from the present test, which can be used to validate computational models for the fire collapse analysis of the test structure. Figure 35 shows the deformed shapes of the test structure after testing. It is observed that transverse frames as a main support member deformed significantly and this triggered the entire collapse of the test structure. 


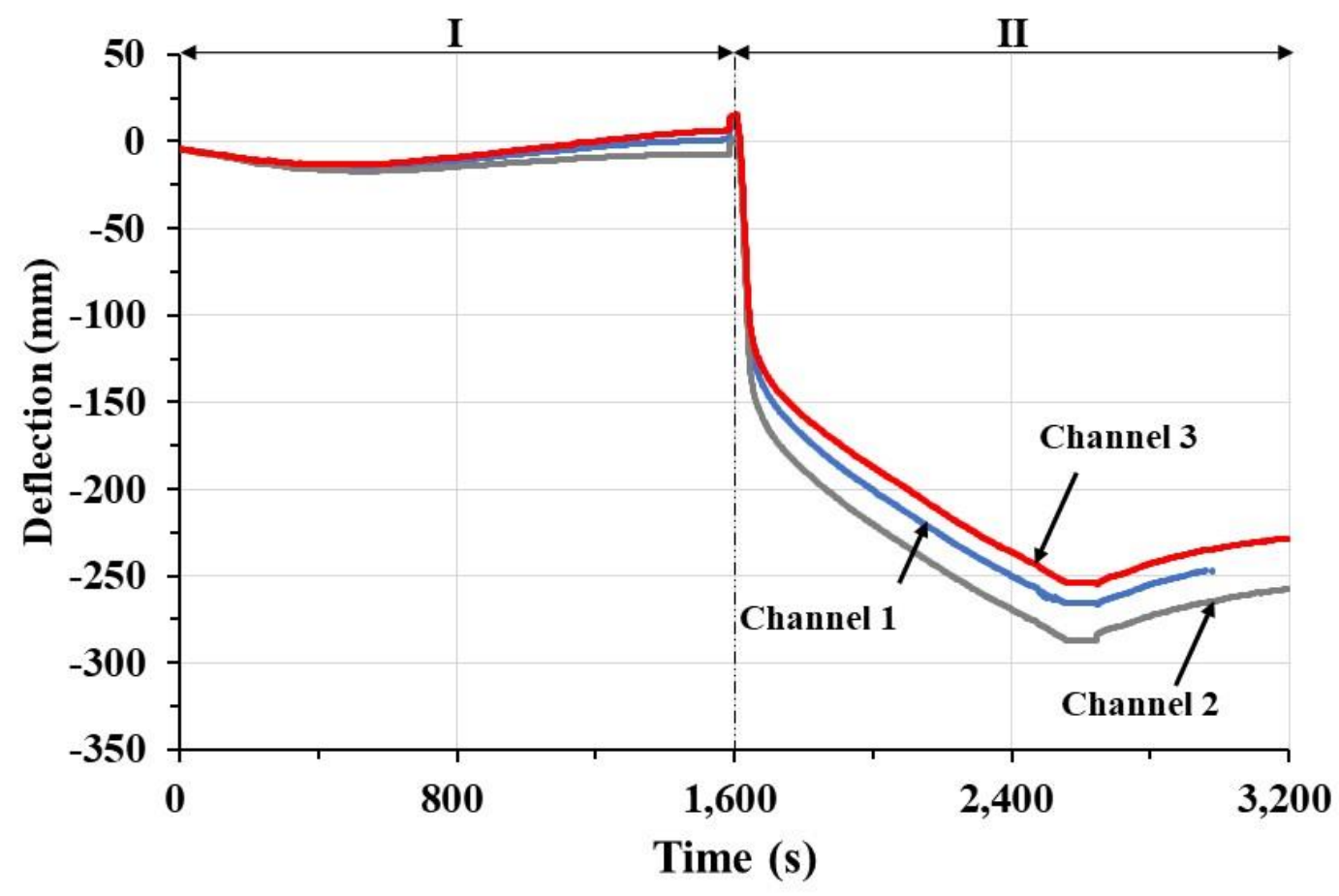

Figure 34. Load-lateral deformation curves of the test structure at the three monitoring points.
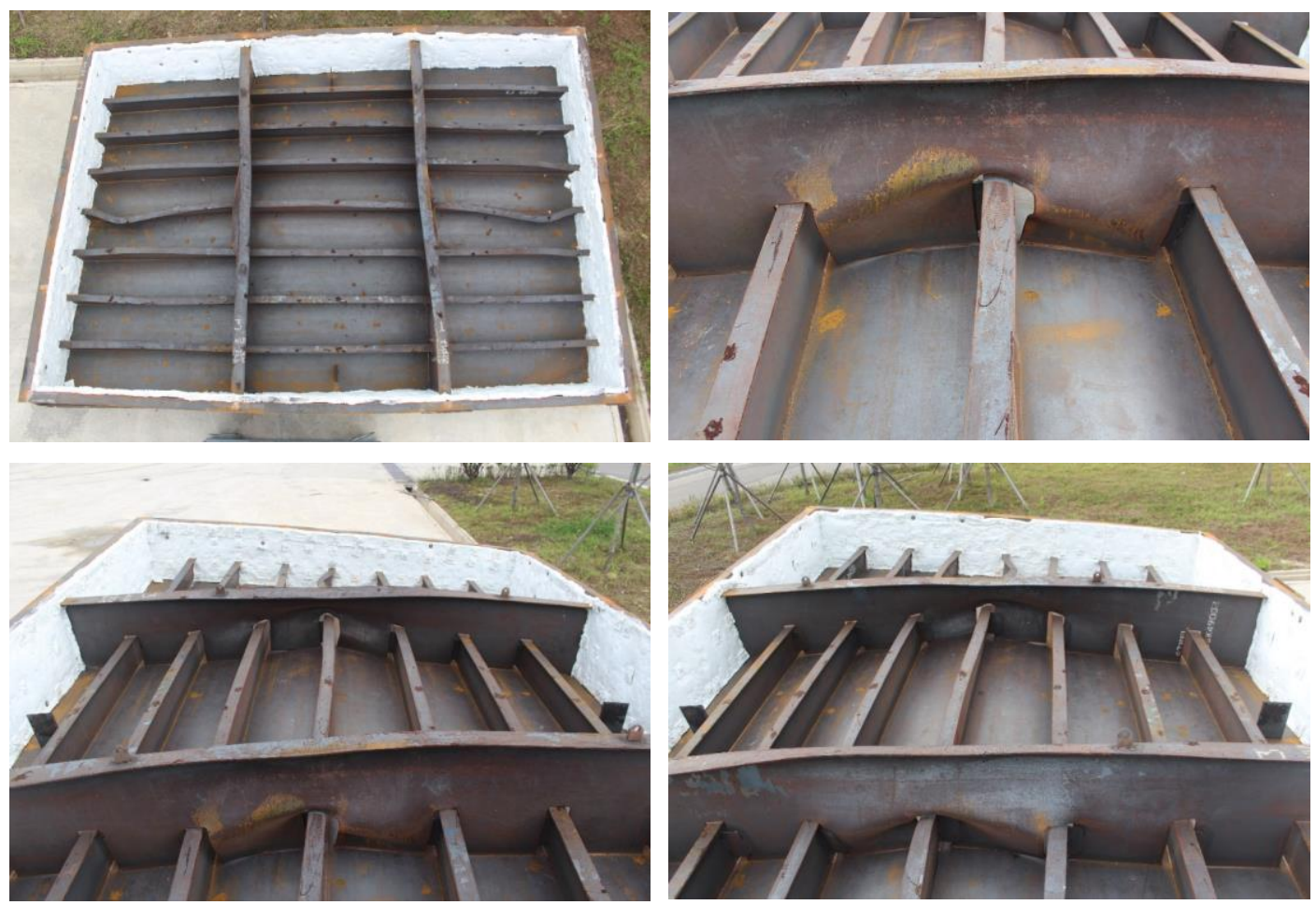

Figure 35. Deformed shapes of the test structure after the test. 


\section{Concluding remarks}

The aim of the paper is to present a fire test database on the collapse of a full-scale steel stiffened plate structure without passive fire protection under lateral patch loading. Based on the study, the following conclusions can be drawn.

1. It was confirmed that setting up the test structure and conducting the full-scale physical tests was successful.

2. Gas cloud temperatures inside the furnace were increased using a burner with a supply of liquefied petroleum gases. It was confirmed that the increase of gas cloud temperatures was controlled successfully to be $15 \%$ below the target ISO 834 fire curve.

3. The time history of the steel temperatures transferred from heat of gas clouds was measured at monitoring points using thermos-electric couple sensors. It was confirmed that the heat transfer analysis using traditional finite element method is in a good agreement with the measurements.

4. Lateral patch loads were applied at the centre of transverse frames using hydraulic loading actuators. The synchronising of the same loading at two points was secured. Patch load applications were made in two steps.

5. The lateral deformations of the test structure were small during the first load step, but it increased dramatically at 1,600 seconds, which can be a critical period of time for fire safety as far as the loading and temperature schemes considered in the present paper are applied. A similar assessment of fire safety can of course be made for different loading conditions.

6. The test database presented in the paper can be useful to validate computational models for the structural failure analysis in fires.

7. Full-scale tests are obviously encouraged further: Passive fire protection is often applied as an effective option to protect entire structures or at least primary strength members exposed to fires. The authors presented a separate article as a sequel to this paper, dealing with the effects of passive fire protection (Paik et al. 2020c).

\section{Acknowledgements}

The work was undertaken at the International Centre for Advanced Safety Studies of the Korea Ship and Offshore Research Institute at Pusan National University which has been a Lloyd's Register Foundation Research Centre of Excellence since 2008.

ORCID

Jeom Kee Paik: http://orcid.org/0000-0003-2956-9359

Giles Thomas: http://orcid.org/0000-0002-6122-4329

\section{References}

ASTM International. 2020. Standard test methods for elevated temperature tension testing of metallic materials \& standard test methods for tension testing of metallic materials. American Association State, West Conshohocken, PA, USA. 
BS. 2014. BS 476-20: Fire tests on building materials and structures-Part 20: Method for determination of the fire resistance of element of construction (general principles). British Steel Institute, London, UK.

Cong S, Liang S and Dong Y. 2005. Experimental investigation of behavior of simply supported steel beams under fire, Journal of Southeast University (Natural Science Edition), Vol.35, pp.66-68 (in Chinese).

DIFK. 2014. Determination of thermal conductivity-ASTM, KCC cerawool new-bio alpha 1200. Test Report 105-218-00-01. Deutsches Institut für Feuerfest und Keramik GmbH, Rheinstrasse, Höhr-Grenzhausen, Germany.

DNV GL. 2018. LNG regulatory update.

http://www.golng.eu/files/Main/20180417/2.\%20Ole\%

20Vidar\%20Nilsen\%20-\%20DNV\%20GL.pdf. Accessed by 15 July 2019.

EMSA. 2019. Annual overview of marine casualties and incidents. Praca Europa 4, 1249-206, European Maritime Safety Agency, Lisbon, Portugal.

EN 1993-1-2. 2005. Eurocode 3: Design of steel structures-Part 1-2: General rulesStructural fire design. European Standard, Brussels, Belgium.

HSE. 2002. Offshore hydrocarbon releases statistics and analysis. Health and Safety Executive, London, UK.

ISO. 1999. ISO 834-1: Fire resistance tests-Elements of building construction-Part 1: General requirements. International Organization for Standardization, Geneva, Switzerland.

Paik JK, Lee DH, Noh SH, Park DK, Ringsberg JW. 2020a. Full-scale testing to the ultimate strength of a steel stiffened plate structure under cyclic compressive loading. Submitted for publication in Structures.

Paik JK, Lee DH, Noh SH, Park DK, Ringsberg JW. 2020b. Full-scale testing to the ultimate compressive strength of a steel stiffened plate structure triggered by brittle fracture at cryogenic condition. Submitted for publication in Ships and Offshore Structures.

Paik JK, Ryu MG, He K, Lee DH, Lee SY, Park DK, Thomas G. 2020c. Full-scale fire testing to collapse of steel stiffened plate structures under lateral patch loading (Part 2) with passive fire protection, Submitted for publication in Ships and Offshore Structures.

Paik JK. 2018. Ultimate limit state analysis and design of plated structures. Second Edition, John Wiley \& Sons, Chichester, UK.

Paik JK. 2019. Advanced Structural Safety Studies with Extreme Conditions and Accidents. Springer, Germany.

Rahmanian I and Wang Y. 2009. Thermal conductivity of gypsum at high temperatures. Acta Polytechnica, 49:16-20.

Ryu MG, He K, Thomas G, Paik JK. 2020. Computational models for the fire collapse analysis of steel stiffened plate structures without or with passive fire protection under lateral patch loading. Submitted for publication.

Wainman DE, Kirby BR (1987). Compendium of UK standard fire test data on unprotected structural steel-1. Report No. RS/RSC/S10328/1/87/B, British Steel Corporation, Rotherham, UK. 
Yi MS, Lee DH, Lee HH, Paik JK. 2020a. Direct measurements and numerical predictions of welding-induced initial deflections in a full-scale steel stiffened plate structures. Submitted for publication in Thin-Walled Structures.

YI MS, Noh SH, Lee DH, Seo DH, Paik JK. 2020b. Direct measurements, numerical predictions and simple formula estimations of welding-induced biaxial residual stresses in a full-scale stiffened plate structure. Submitted for publication in Structures.

Appendix. Time history of lateral deformations for the tested structure at the three monitoring points

\begin{tabular}{|c|r|r|r|}
\hline \multirow{2}{*}{ Time (s) } & \multicolumn{3}{|c|}{ Lateral deformation $(\mathrm{mm})$} \\
\cline { 2 - 4 } & \multicolumn{1}{c|}{$\mathrm{C} 1$} & \multicolumn{1}{c|}{$\mathrm{C} 2$} & \multicolumn{1}{c|}{$\mathrm{C} 3$} \\
\hline 0 & -4.24 & -4.61 & -4.11 \\
\hline 100 & -7.42 & -8.01 & -7.32 \\
\hline 200 & -10.79 & -11.92 & -10.43 \\
\hline 300 & -12.91 & -15.02 & -12.54 \\
\hline 400 & -14.26 & -16.52 & -13.44 \\
\hline 500 & -14.55 & -17.22 & -13.24 \\
\hline 600 & -13.69 & -16.62 & -12.14 \\
\hline 700 & -12.05 & -15.62 & -10.23 \\
\hline 800 & -10.41 & -14.02 & -8.23 \\
\hline 900 & -8.00 & -12.42 & -6.12 \\
\hline 1000 & -6.17 & -11.21 & -3.51 \\
\hline 1100 & -4.05 & -9.61 & -0.90 \\
\hline 1200 & -2.31 & -8.81 & 1.20 \\
\hline 1300 & -0.77 & -7.91 & 3.41 \\
\hline 1400 & 0.39 & -7.51 & 4.92 \\
\hline 1500 & 1.25 & -7.61 & 6.22 \\
\hline 1580 & -122.02 & -141.28 & -113.46 \\
\hline 1600 & -136.28 & -155.5 & -126.9 \\
\hline 1630 & -148.04 & -167.42 & -137.84 \\
\hline 1700 & -165.68 & -185.34 & -154.29 \\
\hline 1800 & -184.09 & -203.46 & -171.35 \\
\hline 1900 & -199.12 & -218.68 & -185.89 \\
\hline 2000 & -212.81 & -232.5 & -198.93 \\
\hline 2100 & -225.91 & -245.72 & -212.48 \\
\hline 2200 & -238.93 & -258.14 & -225.22 \\
\hline 2300 & -250.40 & -269.85 & -236.65 \\
\hline 2400 & -263.50 & -282.57 & -249.70 \\
\hline 2500 & -265.71 & -286.77 & -253.71 \\
\hline 2600 & -260.19 & -278.26 & -248.19 \\
\hline 2630 & -257.88 & -275.86 & -245.88 \\
\hline & & & \\
\hline
\end{tabular}




\begin{tabular}{|l|r|r|r|}
2700 & -253.17 & -271.35 & -241.17 \\
\hline 2800 & -248.05 & -266.35 & -236.05 \\
\hline 2823 & -246.95 & -265.34 & -234.95 \\
\hline 2900 & - & -262.14 & -232.34 \\
\hline 3000 & - & -258.94 & -229.83 \\
\hline 3100 & - & -256.43 & -227.43 \\
\hline 3200 & - & -254.23 & -226.02 \\
\hline
\end{tabular}

